\title{
Hydrologic and Structural Safety Evaluation of Aged Concrete Gravity Dam Using Finite Element Method
}

\author{
Tafesse Fitensa $^{1,}$, , Medhanye Biedebrhan ${ }^{2}$, Sisay Simachew ${ }^{1}$ \\ ${ }^{1}$ Faculty of Water Resources and Irrigation Engineering, Arba Minch Water Technology Institute, Arba Minch, Ethiopia \\ ${ }^{2}$ School of Civil Engineering, Ethiopian Institute of Technology, Mekelle University, Mekelle, Ethiopia
}

Email address:

tatiyihun@gmail.com (T. Fitensa), medhanye@yaho.com(M. Biedebrhan), ssimachew@gmail.com (S. Simachew)

${ }^{*}$ Corresponding author

\section{To cite this article:}

Tafesse Fitensa, Medhanye Biedebrhan, Sisay Simachew. Hydrologic and Structural Safety Evaluation of Aged Concrete Gravity Dam Using Finite Element Method. American Journal of Water Science and Engineering. Vol. 5, No. 4, 2019, pp. 138-154.

doi: 10.11648/j.ajwse.20190504.12

Received: August 9, 2019; Accepted: November 6, 2019; Published: November 17, 2019

\begin{abstract}
History shows that several dams were failed and discharged the stored water which causes incalculable damage on life and property. Several researches disclosed that the methods used to design and re-evaluate concrete gravity dams after the 1970s have shown significant advancement. This starts when contemporary structural analysis methods such as a finite element method were incorporated into computer programs. Structural safety evaluation criterion, design standards and guidelines were also updated. Hence, periodical structural safety evaluation of older dams using state of art techniques is an important activity of the dam experts to ensure a safe operation of dams. This study was focused on hydrological and structural safety evaluation of Koka dam by using HEC-HMS and Abaqus models, based on USACE load combination. The Hydrologic Modeling System, HEC-HMS model was calibrated and used to determine the reservoir elevation reached when the peak outflow resulted from the Probable Maximum Flood (PMF) passes over the spillway. Result of the HEC-HMS model shows that the elevation reached by peak outflow was $1.4 \mathrm{~m}$ lower than the dam crest which indicates no overtopping of the dam due to PMF. The peak reservoir elevation reached when the peak outflow from PMF passes over spillway was used to apply hydrostatic load on the dam. The dam was analyzed by static general method in Abaqus model. The results of Abaqus model indicate that the maximum principal stress in the dam body was under tensile sense near the heel during PMF with the peak magnitude of $0.602 \mathrm{MPa}$. The corresponding minimum principal stress was under compressive sense throughout the base with the peak magnitude of $-0.431 \mathrm{MPa}$. All the results were below the compressive and tensile strength, hence, the dam concrete does not fail under PMF due to material overstressing. The aging of concrete, do not change the stress, but displacement. The results of displacement clearly show a significant increment. This result tells that the aging of concrete reduces the stiffness of the dam and increases its flexibility.
\end{abstract}

Keywords: Hydrological Safety, Structural Safety, Finite Element, Abaqus, HEC-HMS, Aging, Koka Dam

\section{Introduction}

Dams are among the vital infrastructures in advancing the development of one nation. These structures are constructed to store water for various uses. History shows that in all parts of the world several dams were failed and discharged the stored water which causes incalculable damage on life and property [12].

Experiences from the world show that periodic safety evaluation throughout the life of the dam is a means of understanding the condition of structural integrity and need for remedial action [31].

Meisenheimer, in United State Army Corps of Engineers (USACE) technical report indicates that re-evaluation of older dam is necessary as the magnitude of design flood which is currently required is larger due to significant dynamics of catchment hydrology [18]. The author carried out study in the United States of America and observed that many of USACE old concrete gravity dams were failed to fulfill the current flood safety criteria when reevaluated. The main reason from several contributing reasons for this issue 
is that the inflow design flood adopted during the design of these old dams was underestimated.

Zeidan, 2015 and Weiland, 2016 had also supported the necessity of reevaluation of old dams. The authors stated that a number of concrete gravity dams were served for more than half a century. During these periods advanced techniques for estimation of natural phenomena hazards such as floods and earthquakes had emerged. On the other hand, the seismic design criteria, as well as the method of earthquake analysis used for the design of older dams, are now considered outdated. Most codes, regulations, recommendations, and guidelines are also updated. In addition to this, no dam will remain safe constantly even if it was safe during its first operation. Generally, the authors concluded that reevaluation of structural safety of existing dam based on a current state of practice is an important aspect for sustainable use of the dam as well as to extend its service life $[34,36]$.

Similarly, the National Water Academy (NWA), 2014 supported the re-evaluation of older dams by stating that the design and analysis of most old dams, before the 1970s have been based on classical design methods which have many limitations when compared to contemporary approaches. The report further indicates that in 1970s fast computers had emerged and as a result, more sophisticated and powerful structural analysis methods such as the finite element method have been developed [22]. Therefore, reevaluation of older dams using this state of art technologies is essential.

Likewise, Somasundaram \& Calvin, 2009 had stated that many concrete structures around the world are aging [27]. According to these authors aging and deterioration of an old concrete gravity dam is becoming a challenging issue as it has a significant effect on the load resisting capacity of the dam. This problem should have to be checked by performing periodic structural safety review.

Koka dam is one of the oldest concrete gravity dams in Ethiopia being operated for 59 years. It was constructed on Awash River and serves for hydropower generation, irrigation, flood control, and fishery. Even though it is an old dam, there is a gap to get studies on structural stability and safety evaluation that was previously done for the Koka dam.

Hence, the main goal of this study is to evaluate the hydrologic and overall structural safety of Koka dam under Probable Maximum Flood (PMF). Evaluating overtopping of the dam during PMF outflow is one of the specific objectives of this research. Beside this, evaluating the possibility of dam material failure and examining the effect of aging on stress and displacement responses under PMF load combination were included as specific objectives.

\subsection{Description of the Study Area and the Dam}

Ethiopia has 12 major River basins. Koka multipurpose dam is located in Awash River basin, the fourth largest River basin in terms of area. The dam is specifically located at the outlet of the upper Awash sub-basin with the geographical location of $8^{\circ} 28^{\prime} 3$ " N latitude and 39 9'19" E longitude respectively. The upper Awash sub-basin comprises a catchment upstream of Koka dam [15].

The area contributing flow to Koka reservoir is around $11,524.9 \mathrm{~km}^{2}$. The upper awash sub-basin is extended between $8^{\circ} 6^{\prime} 34^{\prime \prime} \mathrm{N}$ to $9^{\circ} 17^{\prime} 59^{\prime \prime} \mathrm{N}$ latitude and $37^{\circ} 57^{\prime} 14^{\prime \prime} \mathrm{E}$ to $39^{\circ} 17^{\prime} 27^{\prime \prime} \mathrm{E}$ longitude in a geographic coordinate system. The maximum and minimum elevation of the upper Awash subbasin ranges between $3575 \mathrm{~m}$ and $1548 \mathrm{~m}$ above mean sea level respectively.

Koka dam is a concrete gravity dam. It is one of the oldest dams in Ethiopia and construction was started in 1957 GC. This dam is being operated for 59 years starting from May 03, 1960GC when it was begun its first operation. The elevation of the dam base and crest level are $1569.4 \mathrm{~m}$ and $1593.2 \mathrm{~m}$ respectively. According to the design drawing obtained from Koka hydroelectric power station, the nonoverflow section of the dam has a vertical upstream with a height of $23.8 \mathrm{~m}$, crest length of $458 \mathrm{~m}$, a top width of $4 \mathrm{~m}$, and a bottom width of $19.92 \mathrm{~m}$. The downstream slope was 10 verticals in 8 horizontals. The overflow section has an inclined face both on upstream and downstream. The upstream and downstream slopes for the overflow section are $1 \mathrm{~V}: 4 \mathrm{H}$ and $10 \mathrm{~V}: 8 \mathrm{H}$ respectively [21]. It has ogee type spillway with a maximum discharge capacity of $1000 \mathrm{~m}^{3} / \mathrm{s}$ at an elevation of $1590.7 \mathrm{~m}$. The crest level of the spillway is at $1585 \mathrm{~m}$. The spillway has four pass ways. Each pass way has a maximum discharge capacity of $250 \mathrm{~m}^{3} / \mathrm{s}$.

\subsection{Sedimentation of Koka Reservoir}

The original maximum and minimum reservoir levels for safe operation of Koka dam were located at $1590.7 \mathrm{~m}$ and $1580.7 \mathrm{~m}$ above mean sea level. According to the initial 1959GC survey, the total reservoir storage capacity at full reservoir level was $1850 \mathrm{Mm}^{3}$ and the usable storage capacity was $1650 \mathrm{Mm}^{3}$. The reservoir area at a maximum water level of $1590.7 \mathrm{~m}$ is approximately $236 \mathrm{~km}^{2}$ [10].

The document received from Awash basin authority describes that the Koka catchment is characterized by degraded land and high peak flash floods which carry a lot of sediment. The report indicates that during the year 2015GC the rainy season falls in an El-Nino year which caused below normal rain and hence inflow to Koka reservoir was reduced. Due to this, the Koka reservoir reduced elevation on November $1^{\text {st }}, 2015$ was at $1587.24 \mathrm{~m}$ and its capacity was $407.8 \mathrm{Mm}^{3}$. This was estimated to be only $41.66 \%$ of the 2015 total reservoir storage capacity. The report also shows the 2015 reservoir storage capacity estimated based on previous 1999 survey was $978.73 \mathrm{Mm}^{3}$ at a full reservoir level of $1590.7 \mathrm{~m}$. This indicates the reservoir has already lost about $40.68 \%$ of its original storage capacity. According to the 2015 estimate, the minimum level at which water can be drawn from the reservoir is $1584 \mathrm{~m}$. This level was taken as a level at which sediment is accumulated behind the dam in this research. The load on a dam due to sediment was calculated having a depth of $14.6 \mathrm{~m}$ above the base of the dam. 


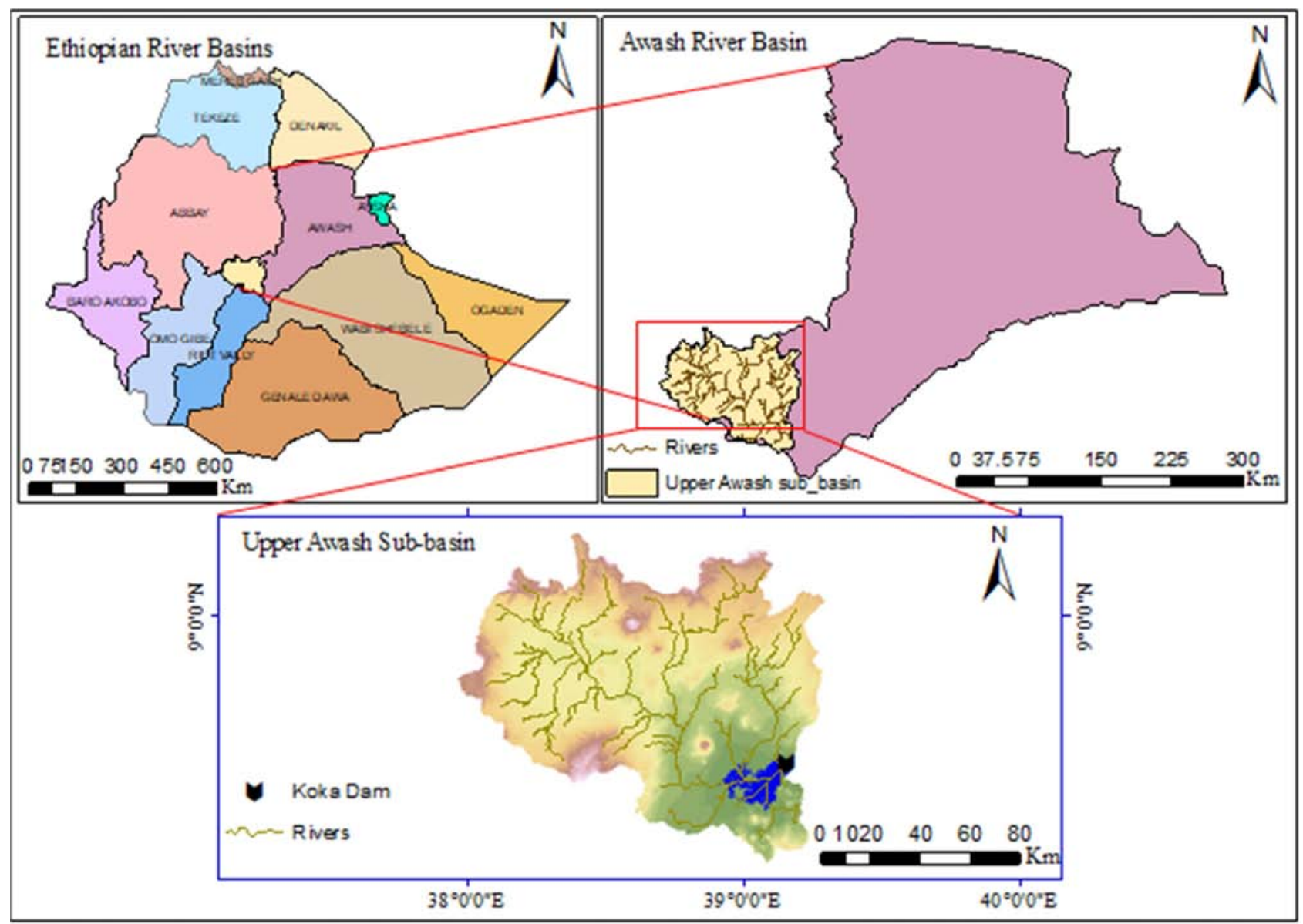

Figure 1. Study area map.

\subsection{Failure Modes of Concrete Gravity Dams}

The failure modes of a concrete gravity dam may be due to overturning, sliding or crushing [1]. According to Ali et al. the overturning or rotational failure about the toe will occur when the point of intersection of the dam base and the line of action of the resultant of all forces acting on the dam lays downstream of the toe i.e. outside of the base [1]. On the other hand, crushing failure may take place if the inherent strength of the dam material fails to withstand the stresses produced due to various loading.

This indicates compression and tension failures will occur due to an exceedance of the allowable compressive and tensile strength of the dam material respectively. Further, Ali et al. added sliding or shear failure will occur when the frictional resistance along the base or any horizontal plane is unable to resist the net resultant horizontal force above the respective plane [1].

\subsection{Basic Load Combinations}

According to Kline et al., (n.d), the load combination that was in use in the latter half of the $19^{\text {th }}$ century was limited only to reservoir empty and full cases [16]. In the 1970s, the load combinations were classified under three main classes: usual, unusual and extreme load combinations. These load combinations are now days used as standard load combinations by several agencies for the design of new concrete gravity dam as well as re-evaluation of old ones. Among the well-known international standards the USACE [28] and United States Bureau of Reclamation (USBR) [29, 30] regulations are essential guidelines used to evaluate the stability of dams. Moftakhar et al revealed that regardless of the use of different analytical methods and procedures, under the same loading condition, the output result is identical for these agencies regulation [19].

USACE manual, [28], is an international and widely applied standard for gravity dam design and analysis in a different part of the world. This manual was previously adopted in the design of gravity dams in Ethiopia. Ethiopian Great Renaissance Dam and Gilgel Gibe III were designed based on the load combinations listed in USACE standard. In this research, the load combination for structural safety evaluation of the Koka dam was done based on USACE, 1995.

\subsection{Stability Criteria and the Factor of Safety}

A factor of safety is a minimum value used to evaluate the load resisting capacity of the dam. USACE, 1995 provides the stability criteria for all load combinations. According to USACE guideline, the stability criterion encompasses stability of the dam against overturning, sliding and overstress. For gravity dam, the factor of safety is based on 
the use of the gravity method of analysis, while for foundation sliding stability are based on the assumption that stress is uniform on the plane under consideration [28]. It was stated that when a finite element method is used for concrete dam analysis, the conventional stability criteria are considered. In order to interpret the output result from finite element program conventional factor of safeties including overturning, overstressing and sliding are used. Overturning can be evaluated by checking the location of resultant force. Shear stress is compared with resisting capacity of the plane under consideration to determine the sliding factor of safety. The compressive and tensile stresses are compared with a compressive and tensile strength of concrete to check overstressing [24]. The overturning effect may also be evaluated based on material overstressing. In real condition, before a dam fails by overturning a material failure due to crushing by compressive force or due to cracking by tensile force takes place. Hence, if the material allowable compressive and tensile stresses are exceeded this can lead to overturning failure.

To evaluate the overall stability of the dam against overturning, sliding and overstressing, the USACE standard uses the following formulae and compares the result with the criteria listed in Table 1 given below.

\subsubsection{Location of the Resultant}

$$
\overline{\mathrm{X}}=\frac{\Sigma \mathrm{M}}{\Sigma \mathrm{V}}
$$

Where, $\Sigma \mathrm{M}=$ integration of bending stresses at the toe, $\Sigma \mathrm{V}=$ Resultant of all vertical forces and $\overline{\mathrm{X}}=$ Location of the resultant force measured from toe.

\subsubsection{Factor of Safety Against Sliding in FEM}

$$
\mathrm{FS}=\frac{\sum\left(\sigma_{\mathrm{i}} * \tan \phi_{\mathrm{i}} * \mathrm{~b}_{\mathrm{i}}+\mathrm{C}_{\mathrm{i}} * \mathrm{~b}_{\mathrm{i}}\right)}{\left(\sum \tau_{\mathrm{i}} * \mathrm{~b}_{\mathrm{i}}\right)}
$$

Where, $\sigma_{\mathrm{i}}=$ Vertical stress normal to sliding plane, $\Phi=$ Angle of internal friction, $\mathrm{C}_{\mathrm{i}}=$ Cohesion property, $\mathrm{b}_{\mathrm{i}}=$ width and $\tau_{\mathrm{i}}=$ Shear resistance of each element on the plane under consideration, by considering unit length of dam.

\subsubsection{Overstressing}

Factor of safety against concrete material overstressing can be checked by comparing the calculated compressive and tensile stresses with the maximum allowable strengths.

Therefore the deviation of Koka dam from standard stability and stress criteria is evaluated based on the abovediscussed requirements.

\begin{tabular}{|c|c|c|c|c|c|}
\hline \multirow{2}{*}{ Loading Condition } & \multirow{2}{*}{ Resultant Location at Base } & \multirow{2}{*}{ Minimum sliding FS } & \multirow{2}{*}{ Foundation bearing pressure } & \multicolumn{2}{|c|}{ Concrete Stress } \\
\hline & & & & Compressive & Tensile \\
\hline Usual & Middle 1/3 & 2.0 & $\leq$ allowable & $0.3 * \mathrm{fc}^{\prime}$ & 0 \\
\hline Unusual & Middle $1 / 2$ & 1.7 & $\leq$ allowable & $0.5 * \mathrm{fc}^{\prime}$ & $0.6 * \mathrm{fc}^{12 / 3}$ \\
\hline Extreme & Within the base & 1.3 & $\leq 1.33 *$ allowable & $0.9 * \mathrm{fc}^{\prime}$ & $1.5 * \mathrm{fc}^{2 / 3}$ \\
\hline
\end{tabular}

Table 1. Stability and stress criteria.

Source: USACE, 1995

\subsection{Trends in Gravity Dam Analysis Methods}

It was understood from history that human societies have been storing water for food production by constructing dams many years ago. This may be witnessed by the remaining of a dam in the present day Jordan, which is believed as it was constructed around 6000 years ago. This dam was traditionally constructed without applying any proper design principles. Utilization of mathematics to calculate dam dimensions had started in the late eighteenth century. This has been advanced through a time when physical logic, by Isaac Newton and Robert Hooke had started to be applied into engineering practice such as dam design [9].

\subsubsection{Origin of the Profile of Equal Resistance}

According to David et al. [9], masonry gravity dams can be built without using any mathematical equation. In the nineteenth century, European engineers understood that it is possible to design these structures by a quantifiable approach.

A French engineer J. Augustin Tortene de Sazilly published subsequent work and contributed in the area of gravity dam design in the early 1850 s. De Sazilly recognizes the hydrostatic force exerted by a given height of water. $\mathrm{He}$ also determined the approximate weight of masonry used in construction. He convinced what he called the "profile of equal resistance".

De Sazilly had developed a cross-section in which compressive stresses at the upstream face during empty reservoir is equal with compressive stresses at the downstream face during full reservoir. By doing this, he found a means of calculating stresses at every section of the dam and he minimized the material required for construction. In 1856, the French engineer F. Emile Delocre used de Sazilly's theory and designed a 57m-high Furens Dam. A few years later a textbook written on gravity dam design recognized Furens dam as the first masonry dam built based on scientific principles [9].

\subsubsection{Development of the Middle Third Rule}

In the early 1870s, Rankine confirmed the validity of de Sazilly and Delocre's previous work. He further recognized that the gravity dam should have enough cross section so that the resultant forces from vertical masonry weight and horizontal water pressure, passes through a center (middle) third of the structure at any horizontal elevation. Rankine concluded the dam will be susceptible for cracking as tensile force are more critical than compressive force if the resultant passes outside the center third. As the location of resultant force is far from center third, the maximum the tensile force 
and the greater the cracking possibility. If the resultant passes beyond the downstream edge the dam totally overturn [9].

The above discussed traditional but sound approach to masonry and concrete gravity dam design was introduced by the beginning of the nineteenth century that persists to the present. Here all the above-discussed design approaches did not consider forces from uplift, silt, and earthquake. Now a day, this traditional approach is modified and termed as gravity method of design by incorporating the uplift, silt, earthquake forces and etc.

The USBR states that the gravity method of analysis is used for preliminary analysis depending on the detail of the design required. This method may be used as a final analysis method for straight gravity dams in a narrow valley. It is convenient for vertical upstream with a constant downstream slope as well as for variable slope on either or both face gravity dams to determine approximate stress. But the assumptions of this method are invalid when the abovediscussed criteria are not fulfilled [29].

\subsubsection{The Trial Load Twist Method}

The bureau of reclamation engineers introduced the coexisting system of horizontal arches and vertical cantilevers termed as trial load analysis method. At first, this method considers only the deflection of the horizontal arch and vertical cantilever. Loads are applied by trial until the deflections of cantilevers and arches at a given point become equal, hence, the name trial load analysis. Later on, the method considers the twisting action of the applied trial load and the name is modified as the trial load twist method [9].

The trial load twist method of analysis assumes that the dam was made of vertical and horizontal elements which are commonly called cantilever and twist structures respectively. This method has remained a fundamental technique of arch dam design, especially in USBR. European engineers do not accept the trial load twist method for gravity dam analysis claiming that this method is more conservative and the computation is very tedious.

USACE, 1995 discusses the trial load twist method is a conventional concrete gravity dam analysis method [28]. This method is considered as more conservative especially when remedial and strengthening of existing dams is necessary. In such cases, USACE recommends the use of a more refined finite element method of analysis as a very useful option.

\subsubsection{Modern Finite Element Method}

The USBR and USACE in their design standard for gravity dam had witnessed that the finite element method of analysis is a more preferable as it is more accurate and many computer packages are available based on this method. Nowadays, the finite element method of analysis is potentially a widely used and accepted computerized method of stress analysis by USBR.

Despite the above-mentioned design standards, several scientific studies had also been done on the structural safety evaluation of concrete gravity dams by applying the finite element method. The researches show that this method of analysis is a powerful and much more accurate in simulating the real situation of gravity dam even by incorporating geometric complexity and nonlinearity.

For instance, Ali et al. have stated that the stability of a gravity dam can be approximately and easily analyzed by two or three-dimensional methods. Simple gravity method, slab analogy method, trial load twist method, finite element method and experimental studies on models are the available methods of gravity dam stability analysis. Out of these methods, the authors prefer the finite element method as a more powerful technique for modeling the dam accurately $[1]$.

The sliding and overturning mode of failure of concrete gravity dam can be analyzed by conventional limit equilibrium method while the overstressing failure is evaluated using simple gravity method or more advanced numerical method such as finite element method [4].

Zeidan, 2016 uses the finite element method to evaluate the effect of foundation flexibility on dam-reservoirfoundation interaction [37]. The author states that the finite element method is the state of art advanced numerical analysis method for concrete gravity dam analysis when compared to conventional Westergaard pseudo-static analysis method. This statement implies that the current trend for the design of a new dam and re-evaluation of old concrete gravity dam is more preferable and realistic if performed based on the finite element method.

According to Patil \& Awari, 2015 the finite element method is a more convenient and primary choice for simulation of in-situ conditions especially when challenging situations such as identification of the response of concrete gravity dam by considering dam-reservoir-foundation interaction is the main concern [23].

Binol, Arya, \& Simi, 2014 have used the finite element method to perform structural analysis of arch dam [3]. They proved that the finite element is a proper numerical technique in a field of engineering where analysis of stress is very complex and finding analytical solution is extremely difficult.

Rizwan, Hanumanthappa, Shyamli, Minoti, \& A K, 2015 have utilized the finite element method for stress analysis of weir block in order to evaluate the structural safety of the dam [25]. The authors have carried out the analysis by considering different loading condition and concluded that the finite element method is capable of simulating tensile stresses of complex structures including openings such as galleries in the dam structure.

Generally, previous studies have shown that the finite element method has far advantages over conventional methods for structural analysis of new dam as well as old dams. The researches reveal that this technique has a powerful capability of simulating dam responses such as stress and displacement under various loading scenarios. It is also proved that this method can model an existing real-life condition and complex geometry more accurately when compared with other classical methods. 


\subsection{Modeling the Dam Using the Finite Element}

The modeling of the dam is a means to know the stress and displacement responses due to the application of several forces on the dam. The finite element method is an appropriate and a state-of-art for numerical modeling of structures.

The finite element method is a numerical technique which is used to find approximate solutions of partial differential equations. It is a more accurate method for approximation of different variables in a physical structure. Application of a finite element method to engineering problems is mostly used to simulate field variables such as stress, displacement, heat transform and etc. in a physical structure.

A powerful commercial finite element package was originated in the 1970s. Abaqus is one of a powerful engineering simulation program. It is based on the finite element method. In this research, Abaqus an advanced finite element based numerical model was used to simulate the variation of stress and displacement throughout the body of the dam. This model is capable of performing structural modeling in 2D and 3D including linear and non-linear analysis [8]. In this research, a 2D non-linear analysis was used with a plain strain element. When one of the dimensions of the structure to be modeled is significantly longer than other dimensions and the load is assumed to be unchanged along the longer side then plain strain analysis is appropriate. When a strain normal to the $\mathrm{X}-\mathrm{Y}$ plane and the shear strains along $\mathrm{X}-\mathrm{Y}$ and $\mathrm{Y}-\mathrm{Z}$ plane are assumed zero then a plain strain element is used [17].

\subsubsection{The Basic Equation of Motions in the Model}

For plane strain element the assumptions are that the normal strain in Z-direction, shear strain in $\mathrm{XZ}$ and $\mathrm{YZ}$ directions are zero i.e. $\varepsilon_{\mathrm{z}}=\gamma_{\mathrm{xz}}=\gamma_{\mathrm{yz}}=0$.

The stress vector $\{\sigma\}^{\mathrm{T}}=\left\{\sigma_{\mathrm{x}} \sigma_{\mathrm{y}} \tau_{\mathrm{xy}}\right\}$ is given by:

$$
\{\sigma\}=[\mathrm{D}][\mathrm{B}]\{\mathrm{d}\}
$$

Similarly the strain $\{\mathcal{E}\} \mathrm{T}=\left\{\mathcal{E}_{\mathrm{x}} \mathcal{E} \mathrm{y} \gamma \mathrm{xy}\right\}$ is represented by:

$$
\begin{gathered}
\{\varepsilon\}=[\mathrm{B}]\{\mathrm{d}\} \\
{[D]=\frac{E}{(1+v)(1-2 v)}\left[\begin{array}{ccc}
1-v & v & 0 \\
v & 1-v & 0 \\
0 & 0 & \frac{1-2 v}{2}
\end{array}\right]}
\end{gathered}
$$

Where, $\varepsilon_{\mathrm{x}}$ and $\varepsilon_{\mathrm{y}}$ are normal strain and $\gamma_{\mathrm{xy}}$ is shear strain along the respective directions. $\{\sigma\}$ represents stress component vectors along the respective directions. $\mathrm{E}$ and $v$ represents elastic modulus of concrete and Poisson ratio while $[\mathrm{D}]$ is a material constitutive matrix for plain strain element. The matrix $[\mathrm{B}]$ is determined from coordinates and area of the element.

The element stiffness matrix for an element of constant thickness, $t$ and area, $\mathrm{A}$ is given by:

$$
[\mathrm{k}]=\mathrm{tA}[\mathrm{B}]^{\mathrm{T}}[\mathrm{D}][\mathrm{B}]
$$

Finally, the model uses equation of motion of the dam for static analysis. The static equation of motion solved by the model is as following.

$$
\mathrm{K}_{e} \mathrm{~d}_{e}=\mathrm{F}_{e}
$$

Where $K_{e}$ is the element stiffness matrix, $d_{e}$ and $F_{e}$ are nodal displacement and force respectively.

\subsubsection{Determination of Concrete Degradation Index for Aged Dam}

The concept of damage in concrete engineering is based on the degradation of a material due to micro-cracks. This microscopic level cracks can lead to a reduction of the effective area which is able to support stresses sufficiently. The loss of rigidity of material can be defined by using a degradation index with relation to un-degraded material [13].

The effect of aging has two significant roles in concrete. On one hand, the concrete gains a compressive strength as the age increases while on the other hand, it also loses its strength due to various chemical and environmental actions [5].

According to Gogoi \& Maity, 2004 the relation adapted to determine the orthotropic damage index is given by:

$$
\mathrm{d}_{\mathrm{i}}=1-\frac{\Omega_{\mathrm{i}}-\Omega_{\mathrm{i}}^{\mathrm{d}}}{\Omega_{\mathrm{i}}}=1-\frac{\Omega_{\mathrm{i}}^{\mathrm{n}}}{\Omega_{\mathrm{i}}}
$$

Where $\Omega_{i}=$ tributary area of the surface in direction $\mathrm{i}$; and $\Omega_{i}{ }^{d}=$ lost area resulting from damage.

The index $\mathrm{i}(1,2,3)$ corresponds with the Cartesian axes $\mathrm{x}$, $y, z$. In this case, the ratio of the net area over the geometrical area may be different for each direction. The value of degradation index $d_{g}$ is given on the scale of 0 to 1 which indicates a total degradation for $\mathrm{d}_{\mathrm{g}}$ value of 1 and no degradation for $\mathrm{d}_{\mathrm{g}}$ value of 0 .

The effective material matrix for the aged dam by considering concrete degradation for plain strain can be expressed as:

$$
\left[D_{\mathrm{d}}\right]=\frac{\mathrm{E}}{(1+v)(1-2 v)}\left[\begin{array}{ccc}
(1-v) \lambda_{1}^{2} & v & 0 \\
v \lambda_{1} \lambda_{2} & (1-v) \lambda_{2}^{2} & 0 \\
0 & 0 & \frac{(1-2 v)\left(\lambda_{1}^{2} \lambda_{2}^{2}\right)}{\left(\lambda_{1}^{2}+\lambda_{2}^{2}\right)}
\end{array}\right]
$$

Where $\lambda_{1}=1-\mathrm{d}_{\mathrm{g}(1)}$ and $\lambda_{2}=1-\mathrm{d}_{\mathrm{g}(2)}$

$\mathrm{E}=$ un-degraded concrete elastic modulus

Assuming the degradation in directions 1 and 2 are equal i.e. $d_{g(1)}=d_{g(2)}=d_{g}$ then the value of $\lambda$ for isotropic degradation index of the aged concrete can be given by:

$$
\lambda=1-\mathrm{d}_{\mathrm{g}}
$$

From the above equation, the degraded constitutive matrix for isotropic degradation can be expressed as

$$
\left[\mathrm{D}_{\mathrm{d}}\right]=\frac{\mathrm{E}}{(1+v)(1-2 v)}\left[\begin{array}{ccc}
(1-v) \lambda^{2} & v \lambda^{2} & 0 \\
v \lambda^{2} & (1-v) \lambda^{2} & 0 \\
0 & 0 & \frac{(1-2 v) \lambda^{2}}{2}
\end{array}\right]
$$


The relation between degraded and un-degraded constitutive material matrix in terms of degradation index can be given by

$$
\begin{gathered}
{\left[\mathrm{D}_{\mathrm{d}}\right]=\lambda^{2}[\mathrm{D}]} \\
{\left[\mathrm{D}_{\mathrm{d}}\right]=\left(1-\mathrm{d}_{\mathrm{g}}\right)^{2}[\mathrm{D}]}
\end{gathered}
$$

According to Gogoi \& Maity, 2004 the degradation index of According to Gogoi \& Maity, 2004 the degradation index of concrete by considering impacts such as time-variant external loading, moisture, and heat transport, freeze-thaw actions, dissolution processes like calcium leaching and chemical reactive reactions can be determined from kinetic law for the aging process. The kinetic law of aging process can be described by normalized process extent $\gamma=0$ for freshly laid concrete and $\gamma=1$ for its completely aged state. The kinetic law of aging process can be stated as

$$
\gamma=\frac{1}{\tau_{\mathrm{a}}}(1-\gamma)
$$

Where, $\tau_{a}=$ the characteristic time of the aging process, which can be assumed to be the design life of the structure.

Integrating the above equation with respect to time yields

$$
1-\gamma=\exp \left(-\frac{\mathrm{t}}{\tau_{\mathrm{a}}}\right)
$$

Replacing $\gamma$ with a damage index $\mathrm{dg}$, the variation of damage index with the age of the concrete structure can be expressed as

$$
1-d_{g}=\exp \left(-\frac{t}{\tau_{a}}\right)
$$

Where, $\mathrm{t}=$ the age of structure in years at which a degradation index is required.

\subsubsection{Estimation of Compressive Strength with Age}

According to Burman et al it was revealed that the compressive strength of concrete increases as the age of the structure increases [5]. This phenomenon was predicted by fitting a curve on a 50 years compressive strength data published by Washa et al, 1989. Gogoi and Maity, 2007 have performed a curve fitting on a compressive strength data of 50 years published by Washa et al. and proposed four models for prediction of a gain of concrete compressive strength with relation to the age of the structure.

Burman et al. 2009 were stated that from the four proposed models the following one is easy to use and it had best fitted to the experimental curve and they adopted this equation for their analysis. In this study the same equation was used.

$$
\mathrm{f}(\mathrm{t})=44.47(\mathrm{t})^{0.08}
$$

Where, $\mathrm{t}=$ the age of the structure at which concrete compressive strength is determined (years).

$\mathrm{f}(\mathrm{t})=$ the compressive strength of concrete at the age of $t$ years $(\mathrm{MPa})$.

\subsubsection{Determination of Un-Degraded and Degraded Elastic Modulus}

Gogoi and Maity, 2004 were used the following empirical formula to predict the compressive strength of concrete at an age of $t$ years.

$$
\mathrm{E}_{\mathrm{o}}=57000 \sqrt{\mathrm{f}(\mathrm{t})}
$$

Where Eo is the value of static elastic modulus at the age of $t$ years (psi)

$f(t)=$ the compressive strength of concrete at age of $t$ years (psi)

Furthermore, according to Burman et al, 2009 the static elastic modulus of concrete at the age of $t$ years can be determined as given in equation below. This equation was adopted for this study.

$$
E_{o}=4733 \sqrt{f(t)}
$$

Where Eo is the value of static elastic modulus at the age of $t$ years $(\mathrm{MPa})$

$f(t)=$ the compressive strength of concrete at age of $t$ years (MPa)

The relation between modulus of elasticity due to gain of compressive strength at $\mathrm{t}$ years, $\mathrm{E}_{\mathrm{o}}$ and the degraded elastic modulus at $t$ years, $E_{d}$ can be expressed by the following formula.

$$
E_{d}=\left(1-d_{g}\right) E_{o}
$$

Where, $d_{g}=$ the degradation index

$\mathrm{E}_{\mathrm{d}}=$ degraded elastic modulus

$\mathrm{E}_{\mathrm{o}}=$ elastic modulus of concrete due to gain of compressive strength.

\section{Methods}

\subsection{Developing Probable Maximum Precipitation}

For structural safety evaluation, a reservoir load on the dam during the PMF is required. In order to determine the PMF, the Probable Maximum Precipitation (PMP) was determined first using Hershfield statistical method, based on World Metrological Organization guideline. The general formula for PMP calculation is:

$$
X_{\mathrm{PMP}}=\overline{\mathrm{X}}_{\mathrm{n}}+\mathrm{K}_{\mathrm{m}} * \mathrm{~S}_{\mathrm{n}}
$$

Where $\mathrm{X}_{\mathrm{PMP}}$ is the probable maximum precipitation, $\overline{\mathrm{X}}_{\mathrm{n}}$ and $\mathrm{S}_{\mathrm{n}}$, are respectively, the mean and standard deviation of a series of annual maxima, and $\mathrm{Km}$ is a frequency factor given by:

$$
\mathrm{K}_{\mathrm{m}}=\frac{\overline{\mathrm{X}}_{\mathrm{n}}-\overline{\mathrm{X}}_{\mathrm{n}-1}}{\sigma_{n-1}}
$$

Where $\overline{\mathrm{X}}_{\mathrm{n}-1}$ and $\sigma_{\mathrm{n}-1}$ are mean and standard deviation of annual maximum series after removing the peak value. The daily rainfall data of 8 stations with 32 years record length were collected from National Metrology Service Agency and 
used to determine a point PMP at all stations. The resulted point PMP can only be used for area around $25 \mathrm{~km}^{2}$, while areal reduction factor should be used for area greater than the specified value. The areal reduction factor of 0.6 can be adopted in East Africa [14]. The same areal reduction value was adopted in this research.

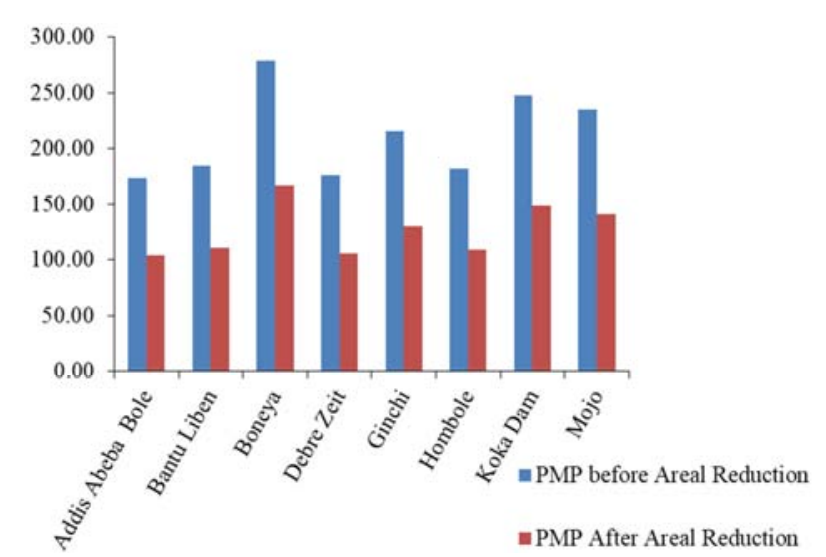

Figure 2. Results of PMP for all stations.

The point value PMP was converted to areal average PMP using Thiessen polygon method.

$$
\overline{\mathrm{X}}_{\mathrm{PMP}}=\frac{\sum_{\mathrm{i}=1}^{8} \mathrm{X}_{\mathrm{PMP}(\mathrm{i})} * \mathrm{~A}_{\mathrm{i}}}{\sum_{\mathrm{i}=1}^{8} \mathrm{~A}_{\mathrm{i}}}
$$

Where $\overline{\mathrm{X}}_{\mathrm{PMP}}$ is the areal average PMP, $\mathrm{X}_{\mathrm{PMP}(\mathrm{i})}$ is $\mathrm{PMP}$ at each station and $A_{i}$ is the area of each station.

ArcGIS 10.1 was used to develop the area enclosed by each rainfall stations.

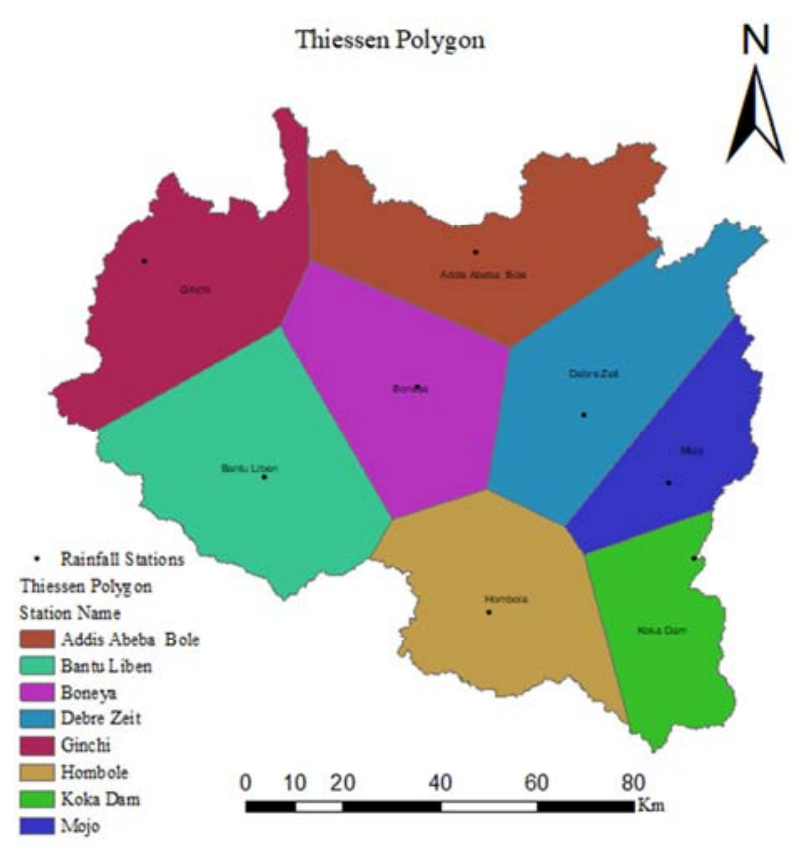

Figure 3. Thiessen polygon for areal rainfall calculation.

The temporal distribution of average areal PMP was determined by applying SCS storm type II. This method was adopted in this study as it was believed to be an appropriate for tropical region rainfall. As it was stated in Soil conservation service manual the rainfall at any time $t$, between 0 and $24 \mathrm{hr}$ is given as a fraction of the $24 \mathrm{hr}$ total cumulative rainfall [33].

$$
\mathrm{P}_{\mathrm{t}}=\text { fraction of } 24 \mathrm{hr} \text { rainfall } * \mathrm{P}_{24}
$$

This temporal value of the probable maximum precipitation was arranged by using the alternate block method technique. The three common conditions of rainfall center i.e. the front-loaded, middle loaded and end loaded were also considered. The most critical temporal arrangement of PMP was determined by providing the front, middle and end loaded distributions for HEC-HMS model and examining which arrangement results in maximum flood magnitude and reservoir elevation. In this research, all the three arrangement of rainfall center had yielded equal reservoir elevation as well as peak outflow. The temporal arrangements of PMP were as following.

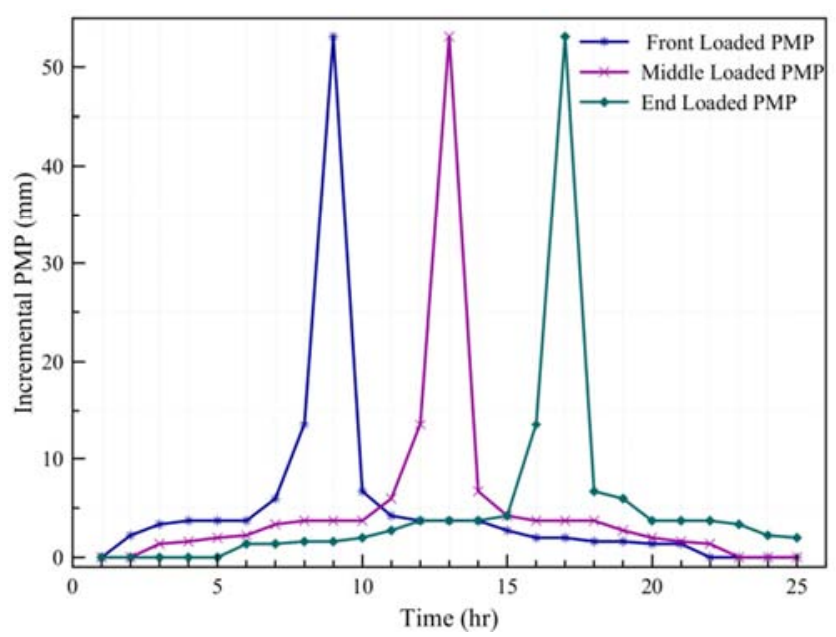

Figure 4. Temporal distribution of a $24 \mathrm{hr} P M P$.

\subsection{Flood Modeling in HEC-HMS}

The hydrologic modeling system is designed to simulate the rainfall and runoff processes of dendritic watersheds. It is designed as it could be applicable to a wide range of geographical locations as well as a wider range of problems. The flood produced by the model can be used for various purposes such as; reservoir spillway capacity determination and flood damage reduction studies [26].

\subsubsection{Model Calibration}

Each model included in the HEC-HMS program has a parameter. In order to estimate runoff from excess precipitation the value of these parameters should be specified. Some of the model parameters cannot be estimated by observation or direct measurement of watershed characteristics. Those parameters which cannot be directly measured can be best found by calibration. Calibration is a systematic search of the value of a parameter until the observed data approximately matches the simulated result [11].

Model calibration is a process of adjusting model 
parameter values until the result of the model resembles the observed data. The degree of match between observed and simulated data is measured quantitatively by the objective function. In the rainfall-runoff simulation, the objective function measures the degree of variation between simulated and observed hydrographs. The process of calibration works in a manner that the parameter values are changed systematically so that the value of the objective function is minimized [7].

\subsubsection{Model Validation}

Model validation is a process of testing the ability of the model to simulate the observed data that are not used previously in the calibration process to an acceptable accuracy. During model validation, the value of model parameters which are already determined during the calibration process should not be changed. The ability of the model to simulate observed and computed hydrographs is measured by objective function [7].

Model validation is a process of determining either the model is suitable or not on predicting runoff in any period outside the calibration period; by keeping the calibrated model parameters. Model validation is very important as it is a means of justifying the capacity of the model to predict runoff on any period of time which is different from the calibration period. Model calibration and validation are often carried out by splitting the data into two groups. Out of the total record period of flow, two-thirds is always used for model calibration while one-third of the observed data is used for model validation [32].

\subsubsection{Model Goodness-of-Fit Indices}

The HEC-HMS program computes the index of goodnessof-fit; in order to compare the simulated hydrograph with the observed one. The goodness-of-fit of the model shows the performance efficiency of the model. An algorithm is included in the program to search the parameter values which yields the best value of an index [11]. The HEC-HMS program version 4.2.1 has included fourteen model performance indicators i.e. objective functions. Among these: peak-weighted root mean square error, percent error in peak, percent error in volume, root mean square error and Nash Sutcliffe are common. As it was discussed in HEC-HMS technical reference manual, only four of the available objective functions are used depending on the need of the analysis.

Different scholars use different model performance criteria. For instance, Asadi \& Boustani, 2013 has used percent error in peak flows (PEPF), percent error in volume $(\mathrm{PEV})$, the coefficient of correlation $(\mathrm{R})$ and relative root mean square error to evaluate the performance of HEC-HMS program on their study of storm flow simulation in Delibajak basin [2]. Furthermore, Moriasi, Arnold, Van Liew, Bingner, Harmel, \& Veith, 2007 in their study of model evaluation guidelines has recommended Nash-Sutcliffe efficiency (NSE), percent bias (PBIAS), and ratio of the root mean square error to the standard deviation of measured data (RSR) as the best statistics for model performance evaluation [20]. These objective functions which are used as model performance evaluation criteria are described below.

\section{i. Root Mean Square Error-observations Standard Deviation Ratio}

According to Moriasi, et al, 2007 the ratio of root mean square error to the standard deviation of observed data is one of the most commonly used error index statistics.

$$
\operatorname{RSR}=\frac{\operatorname{RMSE}}{\operatorname{STEV}_{\mathrm{obs}}}=\frac{\left[\sqrt{\sum_{\mathrm{i}=1}^{\mathrm{n}}\left(\mathrm{Q}_{\mathrm{obs}(\mathrm{i})}-\mathrm{Q}_{\operatorname{sim}(\mathrm{i})}\right)^{2}}\right]}{\left[\sqrt{\sum_{\mathrm{i}=1}^{\mathrm{n}}\left(\mathrm{Q}_{\mathrm{obs}(\mathrm{i})}-\mathrm{Q}_{\text {mean }(\mathrm{i})}\right)^{2}}\right]}
$$

Where RSR $=$ Ratio of mean square error to the standard deviation of measured data

$\mathrm{RMSE}=$ root mean square error,

$\operatorname{STDEV}_{(\mathrm{obs})}=$ standard deviation of observed data.

\section{ii. Nash-Sutcliffe Efficiency}

It is one of the most widely used criteria. This criterion is a good means for use in continuous long-term simulation.

$$
\mathrm{NSE}=1-\frac{\sum_{\mathrm{i}=1}^{\mathrm{n}}\left(\mathrm{Q}_{\mathrm{o}(\mathrm{i})}-\mathrm{Q}_{\mathrm{S}(\mathrm{i})}\right)^{2}}{\sum_{\mathrm{i}=1}^{\mathrm{n}}\left(\mathrm{Q}_{\mathrm{o}(\mathrm{i})}-\overline{\mathrm{Q}}_{\mathrm{o}}\right)^{2}}
$$

Where, NSE = Nash-Sutcliffe Efficiency, Qo(i) = observed flow,

Qs(i) = simulated flow

$\bar{Q}_{o}=$ mean of observed flow

\section{iii. Percentage Bias}

The percentage bias criterion is used to evaluate how well the model simulates the average magnitude of observed and computed flows. This model performance evaluation criterion is used to know the bias of model simulation including the under simulation and over simulation.

$$
\text { PBIAS }=\frac{\sum_{\mathrm{i}=1}^{\mathrm{n}}\left(\mathrm{Q}_{\mathrm{o}(\mathrm{i})}-\mathrm{Q}_{\mathrm{s}(\mathrm{i})}\right)}{\sum_{\mathrm{i}=1}^{\mathrm{n}} \mathrm{Q}_{\mathrm{o}(\mathrm{i})}} * 100
$$

Where, PBIAS = percentage bias,

Qo(i) = observed flow,

$\mathrm{Qs}(\mathrm{i})=$ simulated flow.

Table 2. Performance rating criteria for stream flow.

\begin{tabular}{llll}
\hline Performance rating & RSR & NSE & PBIAS \\
\hline Very Good & $0.00 \leq \mathrm{RSR} \leq 0.50$ & $0.75<\mathrm{NSE} \leq 1.00$ & PBIAS $< \pm 10$ \\
Good & $0.50<\mathrm{RSR} \leq 0.60$ & $0.65<\mathrm{NSE} \leq 0.75$ & $\pm 10 \leq \mathrm{PBIAS}< \pm 15$ \\
Satisfactory & $0.60<\mathrm{RSR} \leq 0.70$ & $0.50<\mathrm{NSE} \leq 0.65$ & $\pm 15 \leq \mathrm{PBIAS}< \pm 25$ \\
Unsatisfactory & RSR $>0.70$ & NSE $\leq 0.50$ & PBIAS $\geq \pm 25$ \\
\hline
\end{tabular}

Source: Moraisi et al, 2007 


\subsection{Developing a Probable Maximum Flood}

The development of PMF in HEC-HMS requires a preparation of a basin model. The first procedure to develop the basin model is preparing the digital elevation model (DEM) of the sub-basin. River shape file was extracted by using the DEM. The DEM with a $30 \mathrm{~m} * 30 \mathrm{~m}$ resolution was used to extract rivers that are in the upper Awash sub-basin. The DEM and River shape files are added to Arc-Map and the terrain preprocessing was done using Arc Hydro tools. DEM manipulation i.e. reconditioning and filling the sinks was performed to remove any inaccuracy from the DEM and prepare it for computation of flow direction, flow accumulation, stream definition and stream segmentation. These processes were followed by catchment grid delineation, polygon processing, drainage line processing, adjoint catchment and drainage point processing. Watershed processing activities such as batch point generation, batch watershed delineation, and flow path tracing was done by proceeding. The HEC-GeoHMS extension was customized and the files already prepared on Arc Hydro tools were added to generate a new project. The basin processing was performed to merge watershed basins as desired. Next to this, the basin characteristics such as river length, river slope, longest flow path, basin centroid, centroidal elevation and the centroidal longest flow path was calculated. Finally, the basins and reaches were named, HMS schematic and background shape files were created and HEC-HMS basin map was generated.

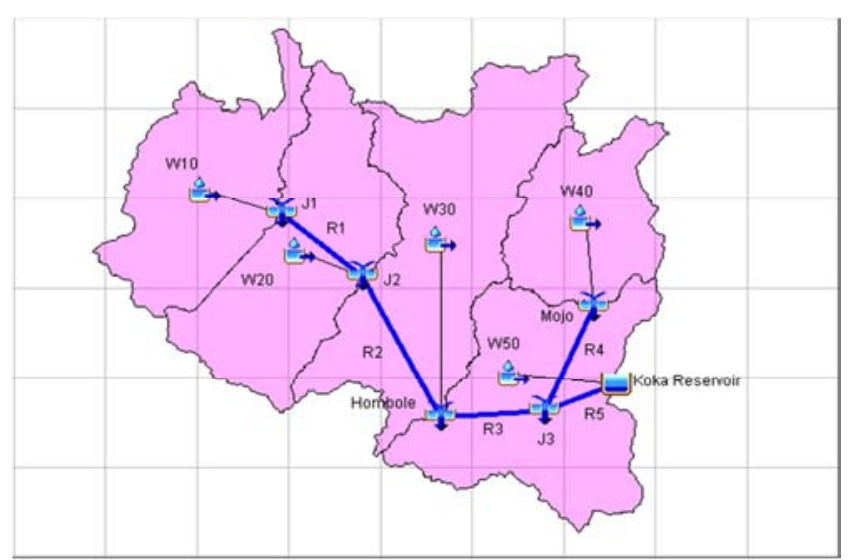

Figure 5. HEC-HMS basin model map.

A flow calibration point was chosen at Hombole station as it has a long term observed discharge data. The HEC-HMS model was calibrated using a flow of seven years starting from $1^{\text {st }}$ January 2000 to $31^{\text {st }}$ December 2006. It was validated using a four years flow from $1^{\text {st }}$ January 2007 to $31^{\text {st }}$ December 2010. The calibrated model was used to generate PMF from the average areal PMP. The developed PMF was given as an inflow to the Koka reservoir and routed. The maximum reservoir water elevation during the passage of the peak outflow was determined. Finally, this elevation was used to determine reservoir hydrostatic load for structural safety evaluation.

\subsection{Structural Analysis Method}

The static general method was used for structural analysis. The non-overflow dam monolith was analyzed by considering the rigid foundation model i.e. fixed base dam. The uplift effect was neglected. The non-linear analysis was incorporated in the analysis. The static reservoir water pressure for PMF load combination was calculated using the reservoir depth of $22.4 \mathrm{~m}$, determined from HEC HMS. This load was applied as a pressure force on the upstream face of the dam using analytical field function in Abaqus software. The static silt pressure was calculated having a height of deposited silt as $14.6 \mathrm{~m}$. The analytical field function was used to apply the load to the dam upstream face in Abaqus. The self-weight of the dam was applied as a gravity load in Abaqus by defining the gravitational acceleration of $-9.81 \mathrm{~m} / \mathrm{s}^{2}$ in the downward direction and concrete density of $2400 \mathrm{~kg} / \mathrm{m}^{3}$.

\subsection{Selection of Element and Optimum Mesh Size}

The Koka dam was modeled using a continuum shell element. A continuum shell element is an appropriate element for modeling of solid parts provided that the thickness of the object is significantly smaller than the other dimensions. The plain strain element was adopted for this research as this type of elements are best suitable for structures with no variation of load along the longer direction. Two shape of the elements i.e. the triangular and quadrilateral shapes with free meshing and structured meshing systems were compared. These elements were CPE6M and CPE8R elements. The CPE6M is a six noded modified quadratic plain strain triangle element while the CPE8R is an eight noded biquadratic plain strain quadrilateral reduced integration element. The convergence test was done by running the Abaqus model with different mesh sizes for each element. The displacement of each element converges when a number of elements are greater than 1000. Depending on the convergence test, the optimum global mesh size was found to be not more than $0.5 \mathrm{~m}$. The CPE6M element with free meshing system and a global mesh size of $0.5 \mathrm{~m} * 0.5 \mathrm{~m}$ was selected for this research.

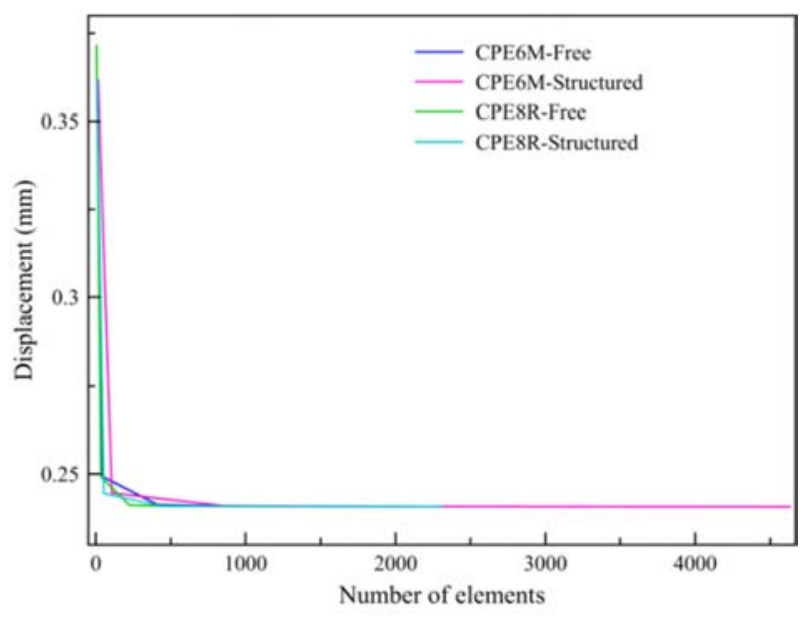

Figure 6. Mesh size optimization. 


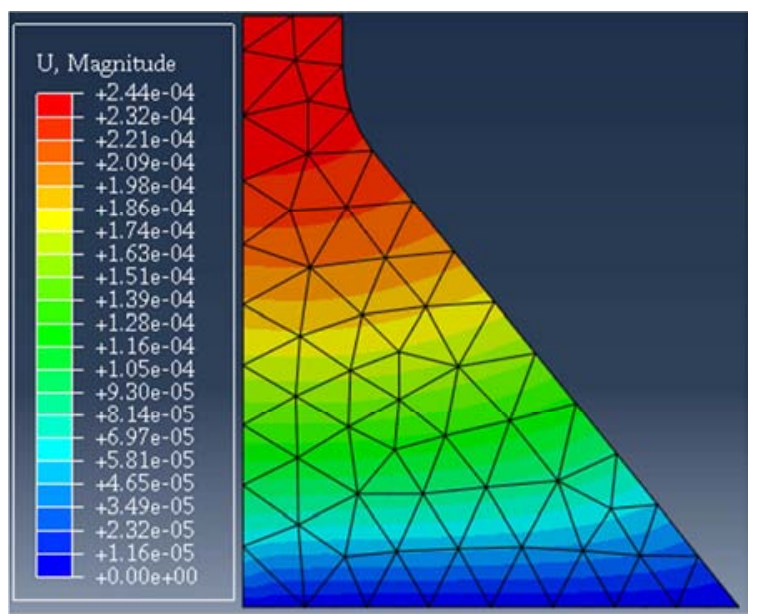

Figure 7. Result of displacement from coarse mesh.

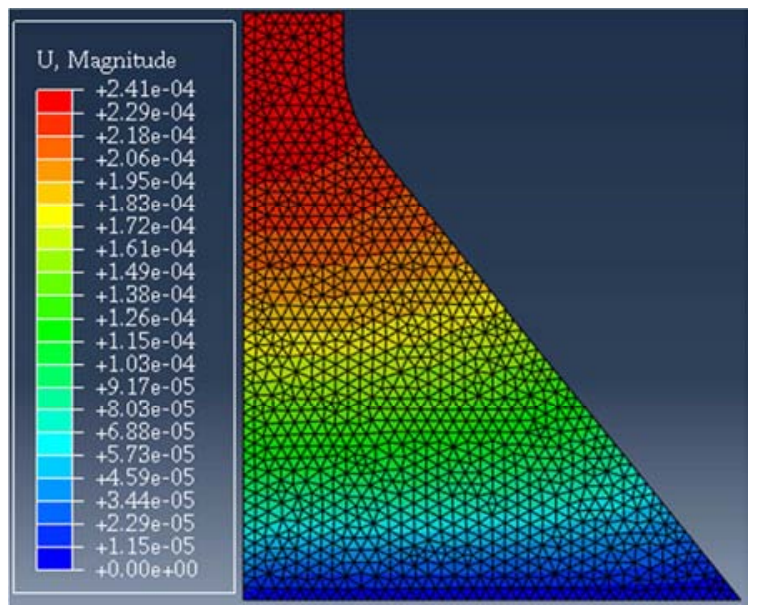

Figure 8. Result of displacement from fine mesh.

Figure 7 and 8 shows the effect of mesh size on displacement response. The global mesh size for the Figure 7 was $2.5 \mathrm{~m} * 2.5 \mathrm{~m}$ while that of Figure 8 was meshed by a global size of $0.5 \mathrm{~m} * 0.5 \mathrm{~m}$. The unit of resultant displacement shown in the legend was in meter.

\subsection{Structural Safety Evaluation}

The Abaqus model yields stress and displacement magnitudes throughout the whole body of the dam in the form of contour. The failure of dam material was checked by comparing the magnitudes of maximum and minimum principal stresses with the allowable concrete compressive and tensile strength. The Abaqus model has different material failure criteria such as Von-Mises stress, Maximum principal stress, Tresca stress, etc. The Von-Mises stress is mainly used for failure evaluation of ductile materials [8]. On the other hand, the maximum principal stress theory is most of the time used for failure evaluation of brittle material such as concrete. Hence, in this research, the Rankine maximum principal stress failure criterion was used. According to this theory, the failure of material can occur if the maximum principal stress developed anywhere in the body of the structure exceeds an allowable material strength.

\section{Results and Discussions}

\subsection{Evaluation of HEC-HMS Model}

The HEC-HMS model was tested first to be used in PMF simulation. The test was done by performing calibration and validation. The observed flow at Hombole gauging station was used for model calibration and validation. The flow of 11 years was used for calibration and validation in the manner that two-third i.e. 7 years flow was for calibration and onethird or 4 years flow for validation.

\subsection{Calibration and Validation Results}

The model calibration and validation show that the observed and simulated flow has a reasonable relation. Three model performance evaluation criteria were selected to evaluate the HEC-HMS program in this research. The selected performance criteria were that which were recommended as best model evaluation criteria by Moraisi et al, 2007. The relation of observed and simulated flow obtained from HEC-HMS model had a NSE of 0.802, RSR of 0.445 and PBIAS of 3.179 for a calibration period. Similarly, the results of these indexes for the validation period were obtained as $0.868,0.364$ and 6.432 respectively. Based on the model performance evaluation indexes the HEC-HMS model was accepted at a very good level to convert the PMP to PMF. The result of performance rating for HEC-HMS model calibration and validation are shown below.

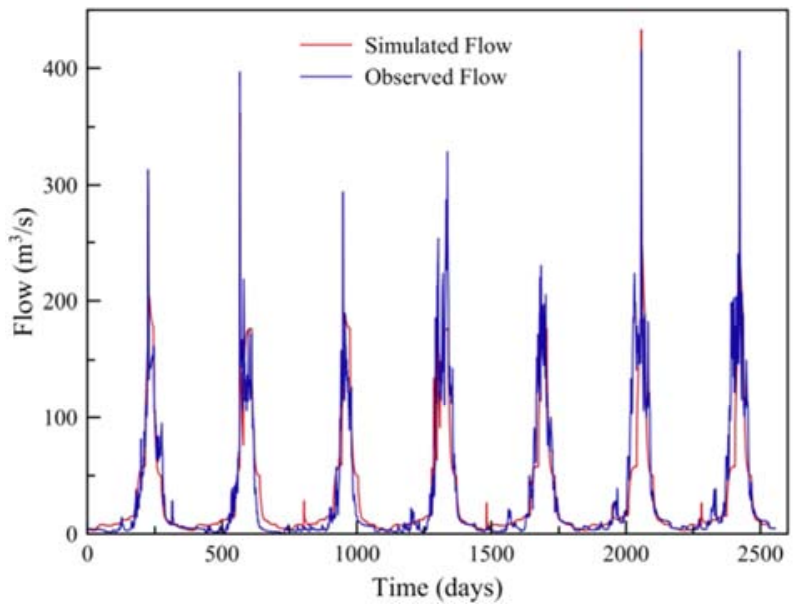

Figure 9. Result of HEC-HMS model calibration from $1^{\text {st }}$ Jan, 2000 to $31^{\text {st }}$ Dec, 2006.

Table 3. Results of performance ratings for the HEC-HMS.

\begin{tabular}{|c|c|c|c|c|c|}
\hline Performance Criteria & Symbol & Calibration & Remark & Validation & Remark \\
\hline Nash-Sutcliffe Efficiency & NSE & 0.802 & Very Good & 0.868 & Very Good \\
\hline Root mean square error to observations standard deviation ratio & RSR & 0.445 & Very Good & 0.364 & Very Good \\
\hline Percent bias & PBIAS & 3.179 & Very Good & 6.432 & Very Good \\
\hline
\end{tabular}




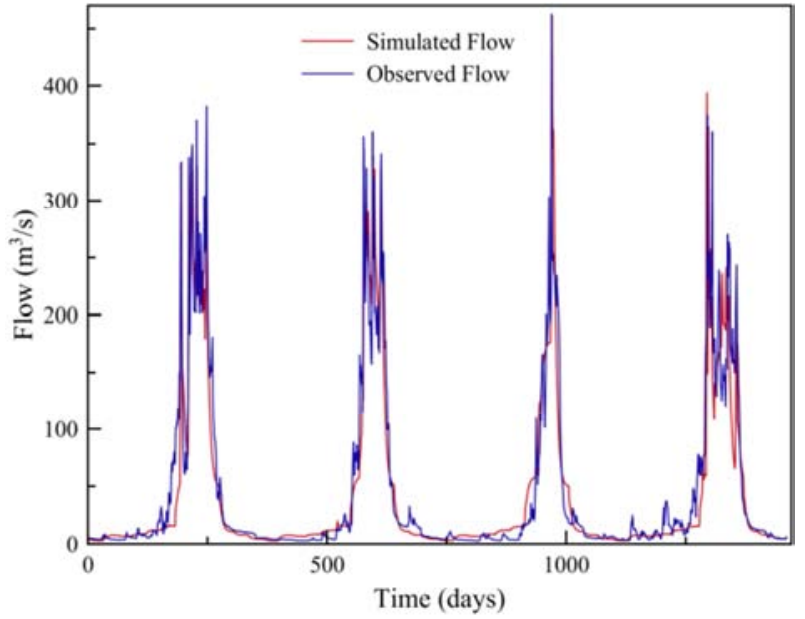

Figure 10. Result of HEC-HMS model validation from $1^{\text {st }}$ Jan, 2007 to $31^{s t}$ Dec, 2010.

\subsection{Evaluation of Dam Overtopping}

The magnitude of areal average probable maximum precipitation resulted from Hershfield statistical method was $206.85 \mathrm{~mm}$. The areal reduction factor of 0.6 was applied and the final average areal PMP value was $124.11 \mathrm{~mm}$. The endloaded temporal arrangement was used. The result of PMF from HEC-HMS model with the end loaded incremental PMP was $4151.8 \mathrm{~m}^{3} / \mathrm{s}$. This was taken as the maximum inflow to Koka reservoir due to the probable maximum precipitation. The peak outflow from reservoir routing was obtained as $701.0 \mathrm{~m}^{3} / \mathrm{s}$. During the passage of this peak outflow, the reservoir elevation was reached a peak elevation of $1591.8 \mathrm{~m}$.

The crest elevation of Koka dam is at $1593.2 \mathrm{~m}$ while the maximum water level set during design is at $1590.7 \mathrm{~m}$. This implies that the reservoir elevation was raised by $1.1 \mathrm{~m}$ above the maximum water level elevation due to the probable maximum flood.

The maximum elevation reached due to the passage of peak outflow from PMF was $1591.8 \mathrm{~m}$ which is $1.4 \mathrm{~m}$ lower than the crest level of the dam. Hence, the dam could not be overtopped due to the probable maximum flood under the current analysis. Depending on this result, the height of water pressure for dam safety evaluation during a probable maximum flood was taken as $22.4 \mathrm{~m}$.

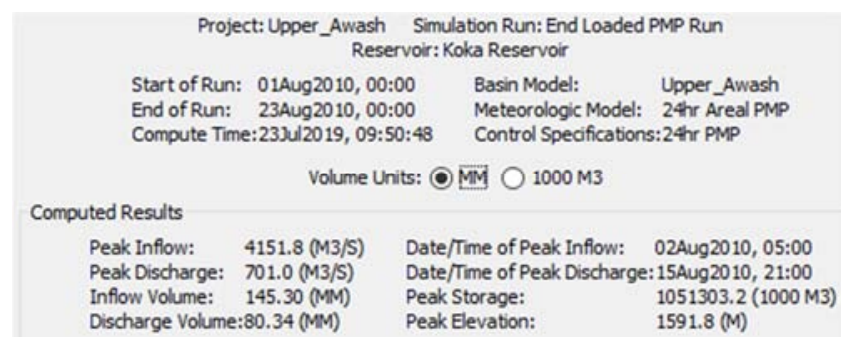

Figure 11. Reservoir peak elevation during peak out flow passes over spillway.

\subsection{Evaluation of Dam Material Failure}

In order to evaluate failure of dam from material overstressing perspective, stress was determined as a contour over the whole body of the dam, and the result was compared with the allowable material strength.

The result obtained from Abaqus model indicates that the maximum principal stress for PMF load combination is in a tensile sense near the dam heel with the peak magnitude of $0.602 \mathrm{MPa}$ located just at the heel. The dam base up to a distance of $2 \mathrm{~m}$ both from the heel and toe is under tensile stress. This indicates that out of the total base width of dam, $10.04 \%$ measured both from heel and toe is under tensile stress while the rest of the dam base is under compressive stress. The analogous minimum principal stress is under compressive sense throughout the whole base of the dam. The peak magnitude occurs at $32.5 \%$ of dam base measured from the heel, with a value of $-0.431 \mathrm{MPa}$.

All the obtained results were within the allowable range of compressive and tensile stress. This indicates that the dam material do not fail under PMF load combination due to material overstressing under the current analysis. The result of the maximum and minimum principal stress contours for PMF load combination was shown in Figures 12 and 13.

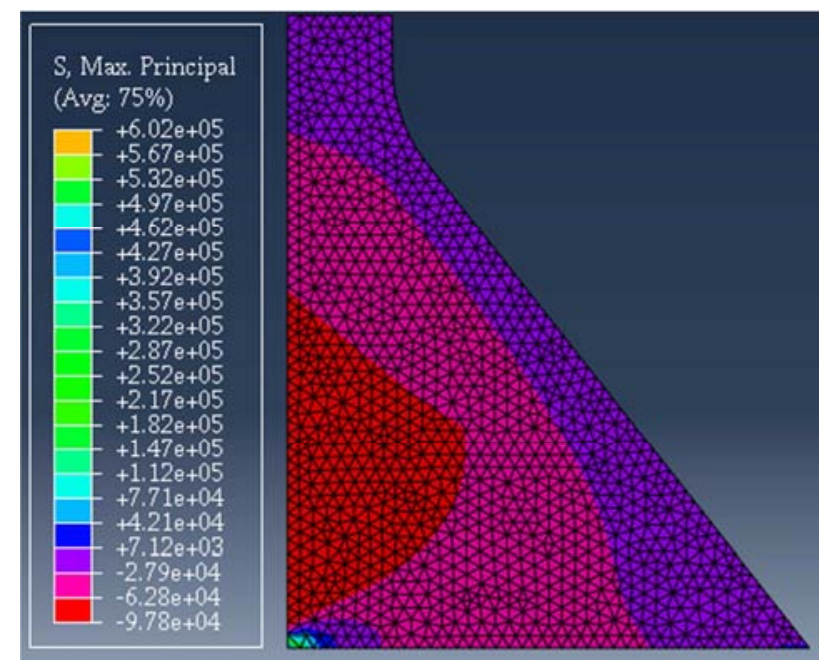

Figure 12. Maximum principal stress.

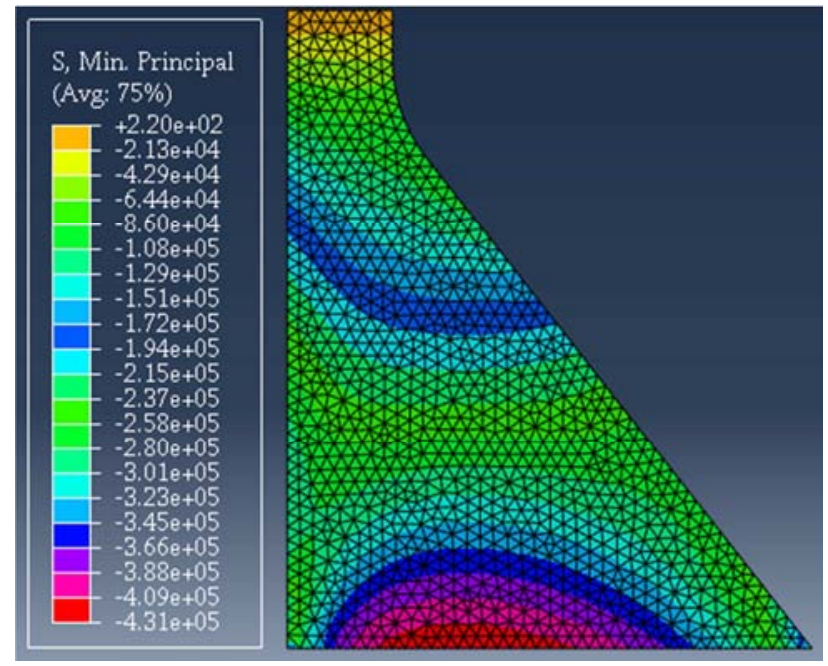

Figure 13. Minimum principal stress. 
The graphical distribution of important stresses along the base of dam during PMF load combination was presented in Figure 14 below.

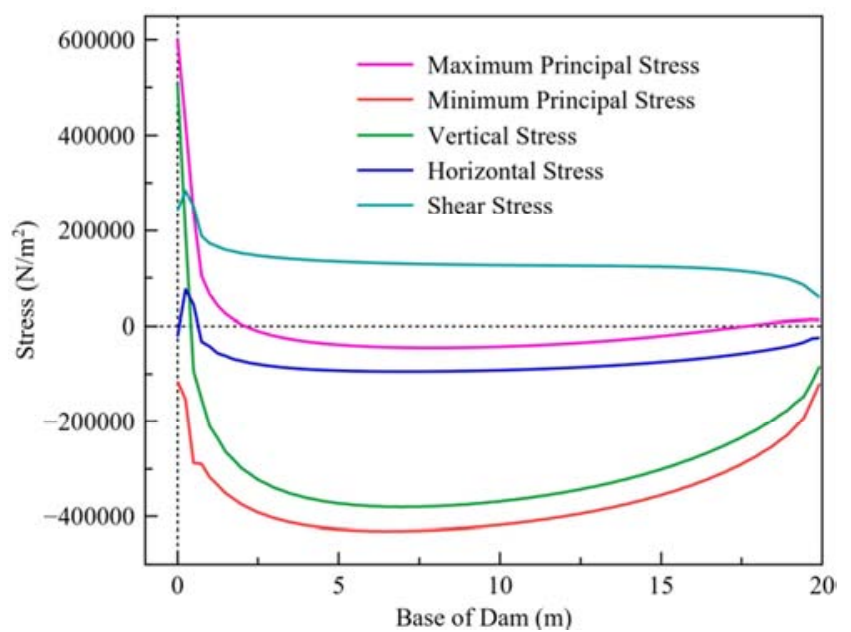

Figure 14. Stress distribution along base of the dam.

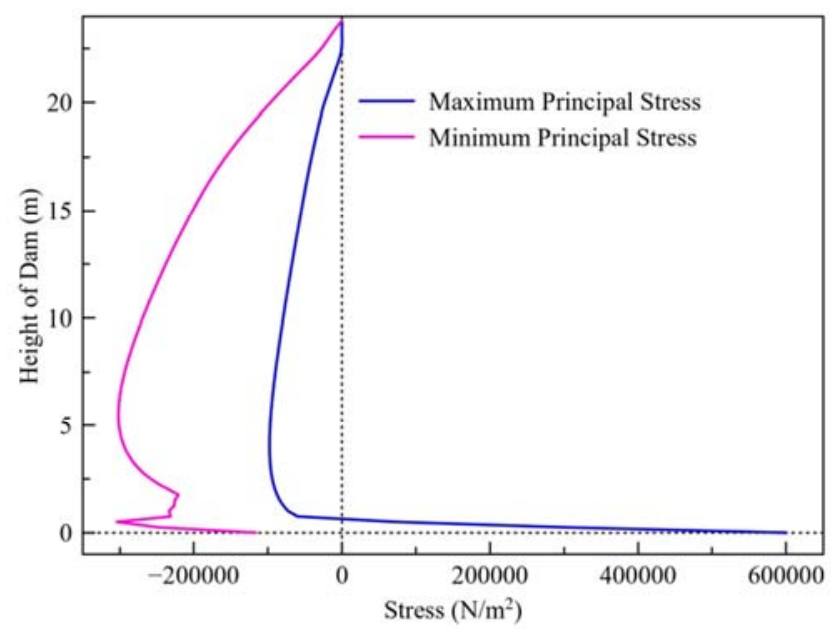

Figure 15. Stress distribution along upstream face.

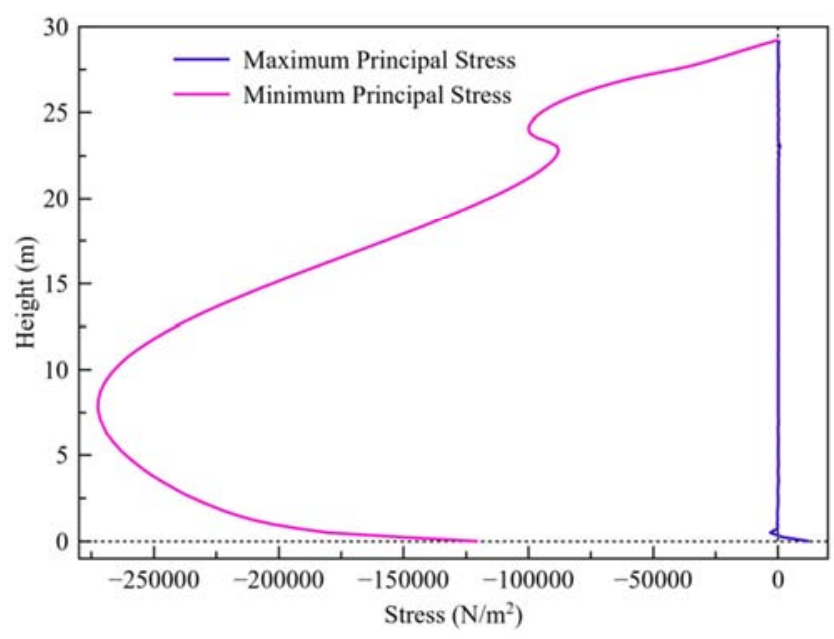

Figure 16. Stress distribution along downstream face.

\subsection{Evaluation of Aging Effect on Stress Responses}

To evaluate the effect of concrete degradation on response of the dam, an empirical model was used to determine degraded concrete properties. The initial concrete elastic modulus was $20.7 \mathrm{GPa}$ for static loading.

After 59 years, the current static degraded concrete elastic modulus was reduced to $11.42 \mathrm{GPa}$. This value has incorporated the effects of aging and chemical reactions. Using the degraded elastic modulus the dam was re-modeled for PMF load combination. The result was used to evaluate the effect of concrete aging on variation of stress and displacement.

The maximum and minimum principal stress obtained from Abaqus model did not changed even if the degraded elastic modulus was used in the re-modeling. The model yields identical maximum and minimum principal stresses for both aged and initial elastic modulus of the dam. It is a known fact that, stress is directly dependent on the magnitude of applied load and inversely related to the effective area that supports the stress. In this research, to determine the effect of aging on stress the loads are kept constant for PMF load combination and the initial elastic modulus was replaced by elastic modulus of aged dam. The stress output did not change. This indicates that the reduction in elastic modulus due to aging, do not tell the reduction in effective area that is capable of supporting stress. Hence, the aging of concrete neither increases nor decreases the stress that developed in the body of the dam. The Figure 16 presented below shows the peak values of maximum and minimum principal stresses with and without considering aging effect.

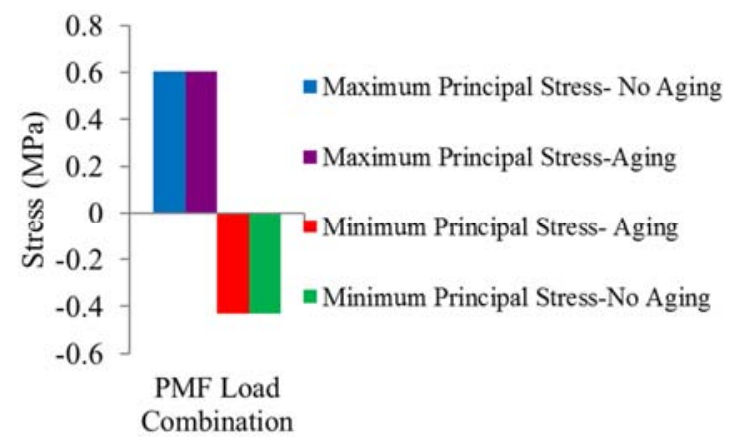

Figure 17. Effect of aging on peak stress along dam base.

Evaluation of Aging Effect on Displacement Responses

The result of modeling dam by considering aged concrete elastic modulus clearly shows a significant increase of displacement. The peak values of horizontal, vertical and resultant displacements of the dam upstream face without considering aging effect was found to be $0.171 \mathrm{~mm}$, $0.179 \mathrm{~mm}$ and $0.241 \mathrm{~mm}$ while these values by considering aging effect was observed as $0.310 \mathrm{~mm},-0.324 \mathrm{~mm}$ and $0.436 \mathrm{~mm}$. The magnitudes of increments of horizontal, vertical and resultant displacement due to aging of concrete were $0.139 \mathrm{~mm}, 0.145 \mathrm{~mm}$ and $0.196 \mathrm{~mm}$.

Similarly the peak values of horizontal, vertical and resultant displacements of the dam downstream face without considering aging effect was found to be $0.168 \mathrm{~mm}$, $0.170 \mathrm{~mm}$ and $0.235 \mathrm{~mm}$ while these values by considering aging effect was observed as $0.305 \mathrm{~mm},-0.308 \mathrm{~mm}$ and 
$0.426 \mathrm{~mm}$. The magnitudes of increments of horizontal, vertical and resultant displacement due to aging of concrete were $0.137 \mathrm{~mm}, 0.138 \mathrm{~mm}$ and $0.191 \mathrm{~mm}$. It is clear from the results that the upstream face of the dam is relatively more displaced than the downstream face.

Generally, the displacement result shows that aging of concrete makes the dam more flexible. In other words, due to aging of concrete the stiffness of the dam is reduced and it becomes less rigid. This indicates that the load resisting capacity of aged dam is less relative to un-aged dam, under the same load combination.

The resultant displacement contour over the whole body of the dam was shown on Figures 18 and 19. Figures 20 and 21 illustrate the variation of displacement along upstream and downstream face respectively, both for aged and un-aged dam. The letters $U 1, U 2$ and $U$ on the figures represents the horizontal, vertical and resultant displacements.

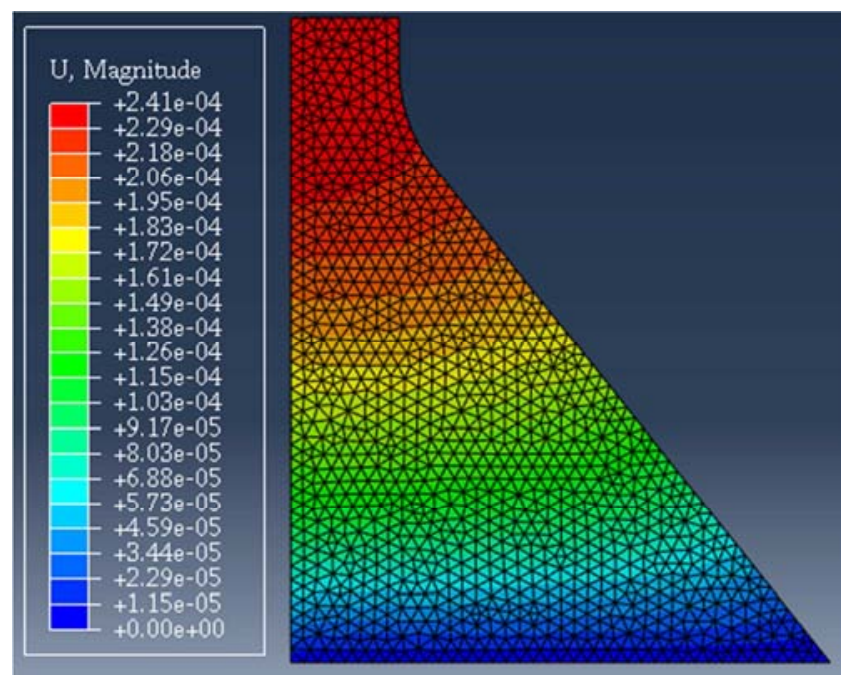

Figure 18. Resultant displacement contour without aging.

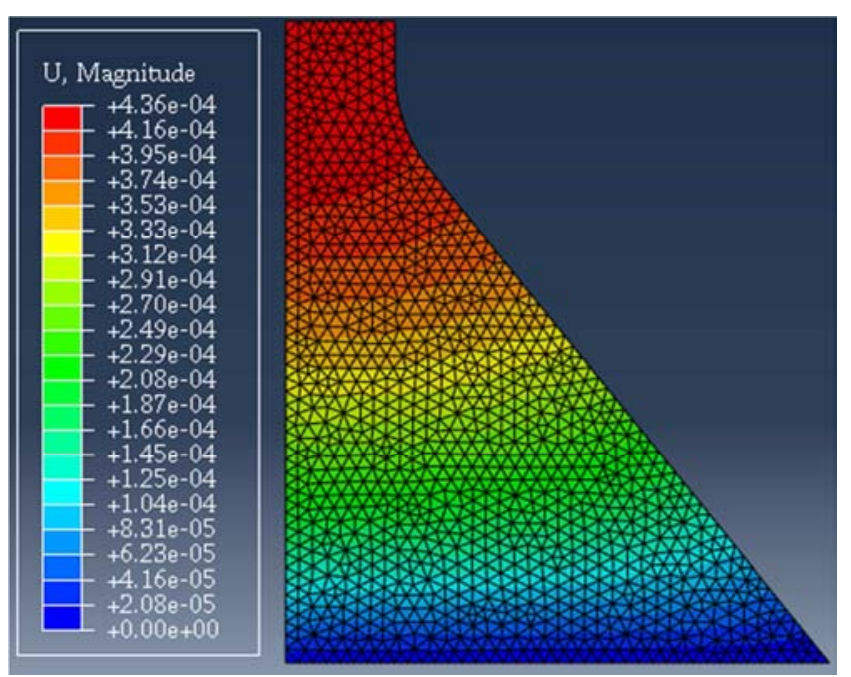

Figure 19. Resultant displacement contour with aging.

The units of displacement magnitude shown on Figure 18 and 19 are in meter.

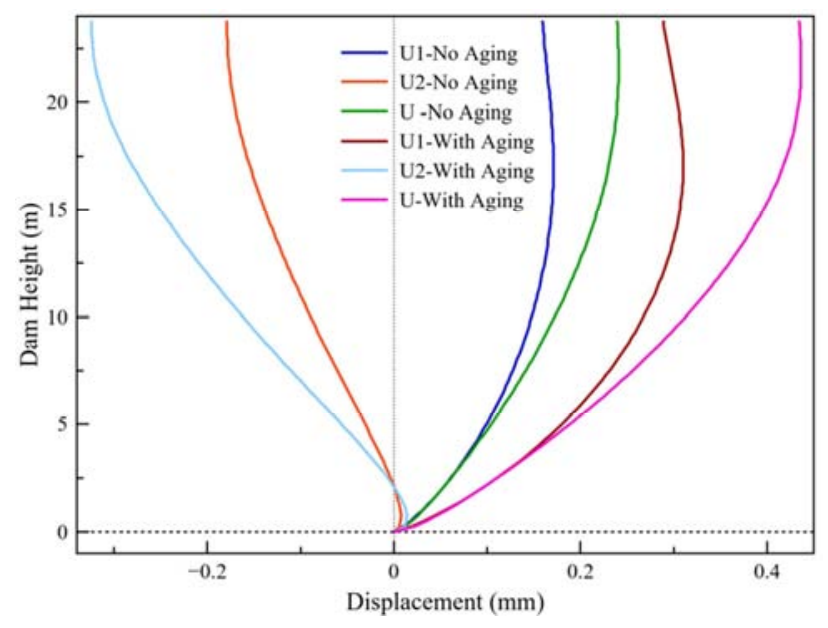

Figure 20. Displacement variation along upstream face.

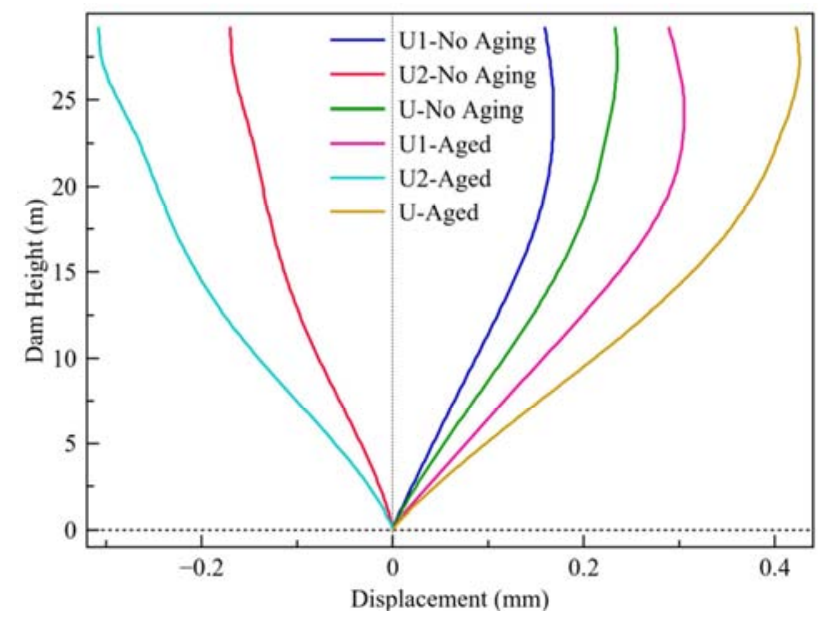

Figure 21. Displacement variation along downstream face.

\subsection{Evaluation of Overall Structural Safety}

Finally the summary of overall structural safety against overturning, sliding and overstressing for Koka dam under probable maximum flood load combination was summarized below. Figure 22 illustrates the location of resultant force along base of the dam.

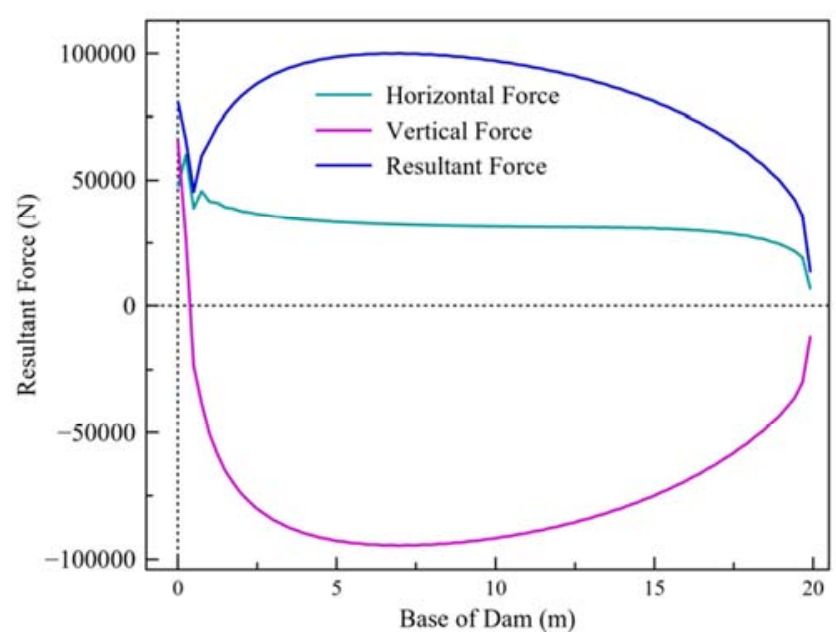

Figure 22. Location of resultant force along the dam base. 
Table 4. Comparison of resultant force location with standard value.

\begin{tabular}{lllll}
\hline Loading Condition & Resultant Location at Base & Standard value & Obtained value & Remark \\
\hline LC7 & Within the base & $0 \leq \overline{\mathrm{X}} \leq 19.92 \mathrm{~m}$ & 12.948 & Safe against overturning \\
\hline
\end{tabular}

The exact locations of resultant force were calculated from results shown in Table 4, taking the toe of the dam as reference. The USACE standard states that in order to avoid overturning, the resultant location has to lie within the base of the dam. The resultant location under PMF load combination was well within the base of the dam; hence, the Koka dam is safe against overturning failure under the current analysis.

The average shear strength of Koka dam concrete was taken as $42 \%$ of the compressive strength. This value is equal to $11.6 \mathrm{MPa}$. The maximum shear stress along the base of the dam for PMF load combination was developed at $0.25 \mathrm{~m}$ from heel with value of $0.283 \mathrm{MPa}$. This value is very far below the shear strength of concrete.

The sliding factor of safety was determined from vertical stress and shear stress. The average value of safety factor for PMF load combination was above the minimum requirement which confirms that the Koka dam is safe against sliding failure under the current analysis. The peak value of shear stress developed along the dam base was also less than the shear strength of concrete; hence, no material failure occurred due to shear on Koka dam.

Table 5. Comparison of sliding factor of safety with standard value.

\begin{tabular}{llll}
\hline Load Combination & Minimum sliding FS & Obtained sliding FS & Remark \\
\hline PMF & 1.3 & 11.984 & Safe against sliding \\
\hline
\end{tabular}

The factor of safety along base of the dam which was calculated at each node is given in Figure 23 below.

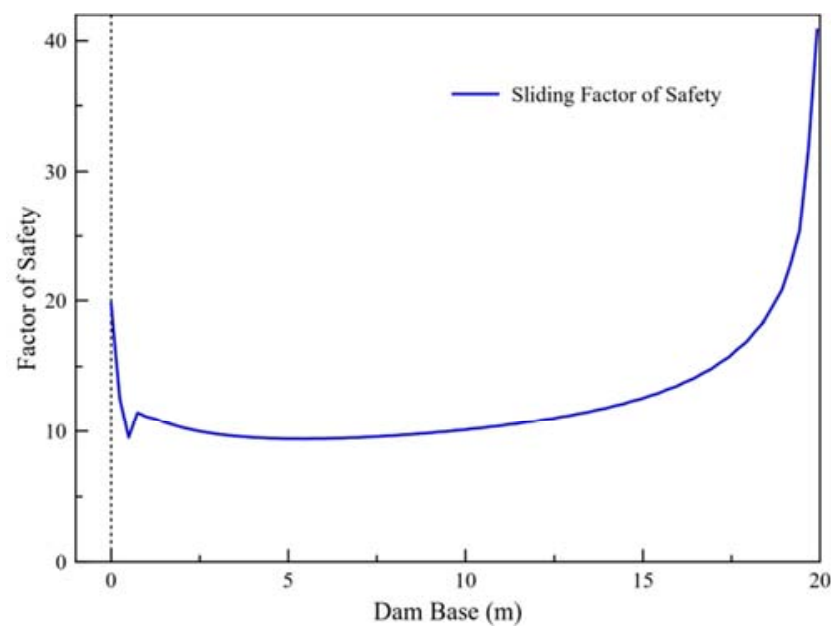

Figure 23. Sliding factor of safety along dam base.

\section{Conclusions}

The structural safety evaluation of Koka dam was carried out using Abaqus, the finite element software, based on the load combination set in USACE standard. The reservoir elevation during passage of peak outflow resulted from PMF was $1.1 \mathrm{~m}$ higher than original flood discharge level, but $1.4 \mathrm{~m}$ lower than the crest of the dam. This result indicates that the spillway capacity is still enough to pass the PMF without overtopping of the dam.

The dam was analyzed by static general method for PMF load combination. The results obtained from Abaqus model indicates that the peak of maximum principal stress developed in the dam body was under a tensile sense near the dam heel. The corresponding peak of minimum principal stress was under compressive sense near the middle base of dam. This result shows that the resultant of all forces for this load combination strike the base around the middle of dam base. Generally, since all the obtained results of stress were well within the allowable range of compressive and tensile limit, the dam concrete do not fail during PMF load combination due to material overstressing under the current analysis.

The aging of concrete, do not change the stress, but the results of displacement clearly show a significant increment.

\section{Recommendations}

The general safety margins of the dam could be better understood if the dam and the surrounding foundation are modeled together as dam foundation interaction rather than fixed base. The dam-foundation interaction has to be considered for future, depending on availability of foundation property data.

The current concrete properties such as elastic modulus, compressive, tensile and shear strength have to be determined in laboratory by taking samples from the dam body. The non-destructive test is also another alternative means for determination of concrete elastic modulus depending on the availability of test equipment's. These are important for determination of actual concrete properties than empirical ones to better figure out the effect of material aging on stress and displacement responses.

\section{References}

[1] Ali, M. H., Alam, M. R., Haque, M. N., \& Alam, M. J. (2012). Comparision of Design and Analysis of Concrete Gravity dam. Natural Resources.

[2] Asadi, A., \& Boustani, F. (2013). Performance Evaluation of the HEC-HMS Hydrologic Model for Lumped and Semidistributed Stormflow Simulation. American Journal of Engineering Research. 
[3] Binol, V., Arya, S., \& Simi, J. (2014). Finite Element Analysis of Arch Dam. IJRET: International Journal of Research in Engineering and Technology.

[4] Bryan, T., Omid, M., Andrea, L., \& C. Richard, D. (2010). Evaluation of the combined finite element discrete element method for the assessment of gravity dam stability. Canadian Dam Association Annual conference.

[5] Burman, A. (2003). Transient Analysis of Aged Concrete Dam-Foundation Coupled System. Doctoral Thesis. Guwahati, India.

[6] Burman, A., Maity, D., \& Sreedeep, S. (2009). The Behavior of Aged Concrete Gravity Dam under the Effect of Isotropic Degradation Caused by Hygro- Chemo-Mechanical Actions. International Journal of Engineering Studies, 109.

[7] Cunderlik, J. M., \& Simonovic, S. P. (2004). Calibration, verification and sensetivity analysis of the HEC-HMS hydrologic model.

[8] Dassault. (2014). Abaqus Analysis. User's Guide, Volume III, Materials.

[9] David, B. P., Donald, J. C., \& Martin, M. V. (2005). The History of Large Federal Dams: Planning, Design, and Construction in the Era of Large Dams.

[10] EEPCO. (2004). Facts About Power Plants in Brief. Addis Abeba.

[11] Feldman, A. D. (2000, March). Hydrologic Modelling System HEC- HMS. Technical Reference Manual. CA, Davis, United States.

[12] FEMA. (2004). Federal Guidelines for Dam Safety.

[13] Gogoi, I., \& Maity, D. (2004). Vulnerability of Aged Concrete Gravity Dams. 13th World Conference on Earthquake Engineering, (p. 5). Canada.

[14] Haile, T. D., \& Awass, A. A. (2016). Embankment dam spillway adequacy evaluation under probable maximum flood, A case of Tendaho dam, Ethiopia. The International Journal of Science and Technoledge.

[15] Halcrow, W. (1989). Master Plan for the Development of Surface Water Resources in the Awash Basin. Addis Abeba: Ethiopian Valleys Development Authority.

[16] Kline, R. A., Davidheiser, S. M., \& Howard, B. (n.d). Current State of the Practice for Existing Gravity Dam Stability Analysis.

[17] Logan, D. (2007). A first Course in the Finite Element.

[18] Meisenheimer, J. K. (1995). The State of Practice for Determining the Stability of Existing Concrete Gravity Dams Founded on Rock. Englewood: Stone and Webster Engineering Coorporation.

[19] Moftakhar, M., \& Ghafouri, H. R. (2011). Comparison of Stability Criteria for Concrete Dams in Different Approximate Methods Based on Finite Element Analysis. Elsevier.

[20] Moriasi, D. N., Arnold, J. G., Van Liew, M. W., Bingner, R. L., Harmel, R. D., \& Veith, T. L. (2007). Model Evaluation
Guidelines for Systematic Quantification of Accuracy in Watershed Simulations. American Society of Agricultural and Biological Engineers.

[21] Norconsultants. (1959). Imperial Ethiopian Government the Koka Project Drawing 1031. Addis Abeba.

[22] NWA. (2014). Analysis and Design of Dams. Training Module. Patna, Bihar.

[23] Patil, S. V., \& Awari, U. R. (2015). Effect of Soil Structure Interaction on Gravity Dam. International Journal of Modern Trends in Engineering and Research.

[24] Ralph W., S., Greg, C., M. Henry Markham, J., \& Jerry L., F. (n.d.). Evaluation of Concrete Dam Stability. Training Aids for Dam Safety.

[25] Rizwan, A., Hanumanthappa, M., Shyamli, P., Minoti, D., \& A K, G. (2015). Stress Analysis by Finite Element Method of Weir Block having Large Size Multiple Openings- A Case Study. International Journal of Emerging Technology and Advanced Engineering.

[26] Scharffenberg, W. (2016). Hydrologic Modeling System HECHMS. User's Manual. CA, Davis, United States.

[27] Somasundaram, V., \& Calvin, C. (2009). Ageing Degradation of Concrete Dams Based on Damage Mechanics Concepts. Springer Science.

[28] USACE. (1995, June 30). Gravity Dam Design. Engineer Manual. DC, Washingiton, United States of America.

[29] USBR. (1976). Design of Gravity Dams. Design manual for concrete gravity dams: A water resource technical publication. Denver, Colorado, United States of America.

[30] USBR. (1977). Design Criteria forConcret Arch and e Gravity Dams. Engineering Monograph No. 19. Denver, Colorado, United States of America.

[31] USBR. (1995). Safety Evaluation of Existing Dams. Water Resources Technical Publication.

[32] Vaze, J., Jordan, P., Beecham, R., Frost, A., \& Summerell, G. (2012). Guidelines for rainfall-runoff modelling. Towards best practice model application. Australia.

[33] Vent, K. M. (1973, April). A method for estimating volumes and rate of runoff in small watersheds. United States of America: Soil Conservation Service.

[34] Weiland, M. (2016). Safety Aspects of sustainable Storage Dams and Earthquake Safety of Existing Dams. Elsevier.

[35] WMO. (2009). Manual on Estimation of Probable Maximum Precipitation. Geneva.

[36] Zeidan, B. A. (2015). State of Art Design and Analysis of Concrete Gravity Dams. ResearchGate.

[37] Zeidan, B. A. (2016). Effect of Foundation Flexibility on Dam-Reservoir-Foundation Interaction. International Water Technology Journal, IWTJ. 


\section{Biography}

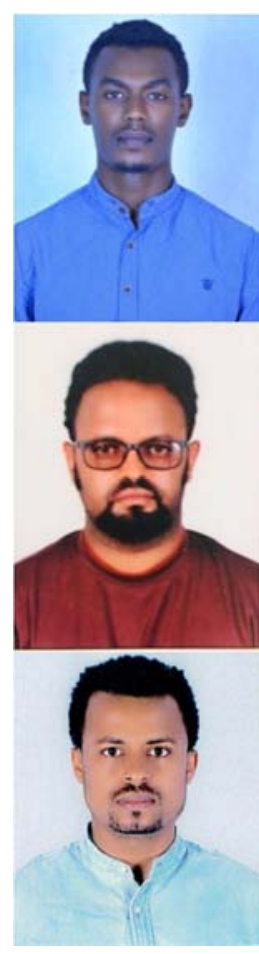

Tafesse Fitensa has received his Bachelor degree in Water Resources and Irrigation Engineering in June 2015 from Arba Minch University. He has obtained his Masters of Science degree in Dam Engineering in June 2019 from Arba Minch University, Water Technology Institute. Currently he is working as Lecturer in Arba Minch Water Technology Institute.

Medhanye Biedebrhan is an Ass. Professor of Structural Engineering; a licensed Practicing Professional Structural Engineer; and a full time academic staff member of the Ethiopian Institute of Technology-Mekelle (EiT-M) under Mekelle University. He has been in the academia for more than 19 years teaching and researching on topics dealing with reinforced concrete and steel structures in his host university and as a guest professor in other seven different universities in Ethiopia. His research interests mainly include structural mechanics in general and stability of shell structures in particular.

Sisay Simachew has obtained his MSc degree in Hydraulic and Hydropower Engineering and BSc in Water Resources and Irrigation Engineering. He has been serving as a senior lecturer and researcher in Arba Minch Water Technology Institute. He has expertise in hydraulics, hydrology, climate change adaptation, irrigation engineering and groundwater modelling. Currently he is a PhD student at Technical University of Munich (TUM), Germany. 